\title{
Diabetes mellitus predicts inferior survival in diffuse large B-cell lymphoma: a propensity score-matched analysis
}

This article was published in the following Dove Press journal: Cancer Management and Research

\author{
Rui Gao' \\ Jin-Hua Liang ${ }^{2}$ \\ Tian-Shuo Man $^{2}$ \\ Li Wang ${ }^{2}$ \\ Hua-Yuan Zhu ${ }^{2}$ \\ Wei $\mathrm{Wu}^{2}$ \\ Lei $\operatorname{Fan}^{2}$ \\ Jian-Yong $\mathrm{Li}^{2}$ \\ Tao Yang ${ }^{l, *}$ \\ Wei $\mathrm{Xu}^{2, *}$ \\ 'Department of Endocrinology, The First \\ Affiliated Hospital of Nanjing Medical \\ University, Jiangsu Province Hospital, \\ Nanjing 210029, People's Republic of \\ China; ${ }^{2}$ Department of Hematology, The \\ First Affiliated Hospital of Nanjing \\ Medical University, Jiangsu Province \\ Hospital, Collaborative Innovation \\ Center for Cancer Personalized \\ Medicine, Nanjing 210029, People's \\ Republic of China \\ *These authors contributed equally to \\ this work
}

Correspondence: Tao Yang

Department of Endocrinology, The First Affiliated Hospital of Nanjing Medical

University, Jiangsu Province Hospital, 300

Guangzhou Road, Nanjing 210029,

People's Republic of China,

Tel +86 2568306466

Fax +862568306466

Email yangt@njmu.edu.cn

Wei Xu

Department of Hematology, The First Affiliated Hospital of Nanjing Medical

University, Jiangsu Province Hospital, 300

Guangzhou Road, Nanjing 210029 ,

People's Republic of China,

Tel +86 $258378 \quad$ I I 20

Fax +86 $258378 \quad$ I। 20

Email xuweil0000@hotmail.com
Purpose: Diabetes mellitus (DM) is associated with elevated cancer risk and poor survival. The objective of this study was to assess the prognostic value of DM in diffuse large B-cell lymphoma (DLBCL).

Methods: Five hundred and fifty-three newly diagnosed DLBCL patients whose treatments included rituximab were recruited. Propensity score-matched method was performed to balance baseline characteristics and eliminate possible bias. Multivariate Cox regression analyses screened the prognostic risk factors in relation to progression-free survival (PFS) and cancer-specific survival (CSS). Receiver-operator characteristic curves and the corresponding areas under the curve (AUC) assessed the predictive accuracy of international prognostic index (IPI) together with DM.

Results: One hundred and nine patients (19.71\%) had pre-existing DM. In the propensitymatched cohort, DM was associated with unfavorable PFS and CSS in rituximab era, and it was an independent risk factor for both inferior PFS and CSS, especially in patients with age $\leq 60$ years, IPI 0-2, B symptoms and lactate dehydrogenase $\leq$ upper limit of normal. Prediabetics also demonstrated inferior prognostic outcomes compared to patients with no diabetic tendency. DM as one additional point to IPI had larger AUC compared with IPI alone in CSS prediction and could improve the prognostic capacity of IPI.

Conclusion: The results indicate that preexisting DM is an important risk factor for survival. It could help predict life expectancy and build refined prognostication models for DLBCL.

Keywords: diffuse large B-cell lymphoma, diabetes mellitus, progression-free survival, cancer-specific survival, propensity score-matched analysis

\section{Introduction}

Diabetes and malignancy are multifactorial heterogeneous diseases, and both have witnessed a rapid increase in prevalence owing to environmental and lifestyle changes. Accumulating evidence suggested that diabetes mellitus (DM) was correlated with elevated cancer risks, including liver, ${ }^{1}$ pancreatic, ${ }^{2}$ colorectal ${ }^{3}$ and breast cancer. ${ }^{4}$ Concerning non-Hodgkin lymphoma (NHL), three meta-analyses of observational studies reported that the risk ratio (RR) of developing NHL in patients with diabetes was 1.19 (95\% CI: $1.04-1.35),{ }^{5} 1.22$ (95\% CI: $\left.1.07-1.39\right)^{6}$ and 1.79 (95\% CI: $1.30-2.47){ }^{7}$ respectively. Possible underlying biological mechanisms of diabetes-promoting carcinogenesis were discovered, such as hyperglycemia, hyperinsulinemia and chronic inflammation. 
Diffuse large B-cell lymphoma (DLBCL), the most common lymphoid malignancy in adults, is characterized by wide clinical phenotypes and molecular heterogeneities. ${ }^{89}$ Although the introduction of rituximab to CHOP (cyclophosphamide, doxorubicin, vincristine and prednisone) reformed the treatment of DLBCL, the long-term survival of one-third patients is still poor due to relapse and refractory after initial chemoimmunotherapies. ${ }^{10}$ The international prognostic index (IPI), which consists of five clinical parameters, is the current standard prognostication system for DLBCL. However, it was proven insufficient in predicting the prognosis of highrisk patients in rituximab era ${ }^{11}$ and revealing the underlying biological differences. Therefore, novel prognostic factors are urgently required in identifying high-risk DLBCL patients and facilitating treatments in personalized medicine.

The evidence regarding the prognostic impact of DM on lymphoma remains limited and inconclusive. No literature to date has focused on the correlation between DLBCL and DM, and the prognostic value of DM in DLBCL. To address this issue, our study indicated preexisting DM as a predictor of inferior prognosis in DLBCL by propensity score-matched (PSM) analyses. Considering the heterogeneity of different NHL subtypes, focusing on DLBCL would present more accurate and specific results.

\section{Methods}

\section{Ethics approval and consent to participate}

This study was approved by the Ethics Committee of the First Affiliated Hospital of Nanjing Medical University. All aspects of the study, including measurements for glucose levels and other periodical clinical and laboratorial checkups, were performed according to the principles of the Declaration of Helsinki (64th, 2013). Written informed consent and permissions for the possibility of utilizing their clinical data anonymously in the future were obtained from all subjects involved in this study at the time of first DLBCL admission.

\section{Patients}

Six hundred and twenty-eight consecutive subjects with newly diagnosed DLBCL between January 2008 and November 2016 from the First Affiliated Hospital of Nanjing Medical University were retrospectively enrolled. Seventy-five patients were excluded for not in accordance with the following criteria: 1) with complete clinical information and follow-up data; 2) without previous malignancies; 3) negative for $\mathrm{HIV}$; 4) received chemoimmunotherapies as first-line treatment; 5) patients having dose reduction in chemoimmunotherapies (cyclophosphamide and anthracycline) owing to blood urea nitrogen $(\mathrm{BUN})$ or creatinine $(\mathrm{SCr})$ levels at diagnosis more than 1.5-fold upper limit of normal, or leftventricular ejection fraction below $55 \%$ were excluded to avoid confounding effect; 6) patients who died of accident or other medical conditions with no relation to DLBCL were excluded in order to analyze the prognostic value of DM on DLBCL-specific deaths. The flowchart of the study population is presented in Figure S1.

\section{Data collection}

All DLBCL patients were managed and treated in the inpatient department, while the follow-up examinations were conducted in the outpatient department. Baseline clinical characteristics, which consist of gender, age, IPI, Ann Arbor stage (I-IV), Eastern Cooperative Oncology Group (ECOG) performance status (PS), the number of extranodal sites, Hans classification, symptoms, previous cancer diagnosis, lymphoma treatments and response to therapy were available from medical records and hospital registries. Laboratorial and imageological data including blood biochemical examination (lactate dehydrogenase [LDH], albumin, etc.), renal function test (BUN, SCr, etc.), etiological test (hepatitis $\mathrm{B}$ virus, hepatitis $\mathrm{C}$ virus, treponema pallidum and HIV) and positron emission tomography-computed tomography (PET-CT) and echocardiography were routinely performed on every patient upon first DLBCL admission and were accessible from the hospital-based laboratorial and imageological service.

Among these 553 cases, 404 (73.06\%) were treated with R-CHOP (rituximab, cyclophosphamide, doxorubicin, vincristine and prednisone), 118 (21.34\%) with dose-adjusted (DA)-EPOCH (etoposide, prednisone, vincristine, cyclophosphamide and doxorubicin) plus rituximab, 22 (3.98\%) with R-CHOP like regimens including R-CDOP (rituximab, cyclophosphamide, pegylated liposomal doxorubicin, vincristine and prednisone) and R-CEOP (rituximab, cyclophosphamide, epirubicine, vincristine and prednisone) and 9 (1.63\%) with R-mini CHOP (rituximab combined with low-dose CHOP). With regard to the relative dose intensity of chemotherapies, both diabetics and nondiabetics received standard treatments without delay or dose reduction (including steroid) due to hyperglycemia or other diabetic complications. The dose of rituximab is $375 \mathrm{mg} / \mathrm{m}^{2}$ in all rituximab-based chemoimmunotherapies. In both groups for CHOP, the dose intensity is cyclophosphamide 750 $\mathrm{mg} / \mathrm{m}^{2}$, doxorubicin $50 \mathrm{mg} / \mathrm{m}^{2}$ and vincristine $1.4 \mathrm{mg} / \mathrm{m}^{2}$ 
(maximum $2 \mathrm{mg} / \mathrm{m}^{2}$ ) on day 1 and prednisone $60 \mathrm{mg} / \mathrm{m}^{2}$ on days $1-5$. EPOCH is composed of etoposide $50 \mathrm{mg} / \mathrm{m}^{2}$, vincristine $0.4 \mathrm{mg} / \mathrm{m}^{2}$ and doxorubicin $10 \mathrm{mg} / \mathrm{m}^{2}$ continuous infusion on days $1-4$, cyclophosphamide $750 \mathrm{mg} / \mathrm{m}^{2}$ on day 5 and prednisone $60 \mathrm{mg} / \mathrm{m}^{2}$ on days $1-5$. For CDOP, the specific dose is cyclophosphamide $600 \mathrm{mg} / \mathrm{m}^{2}$, pegylated liposomal doxorubicin $30 \mathrm{mg} / \mathrm{m}^{2}$ and vincristine 1.4 $\mathrm{mg} / \mathrm{m}^{2}$ (maximum $2 \mathrm{mg} / \mathrm{m}^{2}$ ) on day 1 and prednisone 60 $\mathrm{mg} / \mathrm{m}^{2}$ on days $1-5$, while for CEOP the specific dose is cyclophosphamide $750 \mathrm{mg} / \mathrm{m}^{2}$, epirubicine $70 \mathrm{mg} / \mathrm{m}^{2}$ and vincristine $1.4 \mathrm{mg} / \mathrm{m}^{2}$ (maximum $2 \mathrm{mg} / \mathrm{m}^{2}$ ) on day 1 and prednisone $60 \mathrm{mg} / \mathrm{m}^{2}$ on days $1-5$. Moreover, the combination of mini-CHOP includes cyclophosphamide $400 \mathrm{mg} / \mathrm{m}^{2}$, doxorubicin $25 \mathrm{mg} / \mathrm{m}^{2}$ and vincristine $1 \mathrm{mg}$ on day 1 , and prednisone $40 \mathrm{mg} / \mathrm{m}^{2}$ on day $1-5$. The numbers of patients according to diabetic status distributed by treatment types are presented in Table 1.

The final evaluation of response was performed after 6-8 cycles of chemotherapies, and lymphoma response was classified according to the International Workshop Criteria. ${ }^{12}$ Diabetic and nondiabetic patients were given the comparable number of treatment cycles. Their antidiabetic medications before DLBCL admission were still used as basic glycemic control during the entire hospitalization. Insulin was also applied for poorly controlled hyperglycemic patients.

\section{Definition of preexisting DM and measurement for plasma glucose level}

Preexisting DM referred to patients having any one of the following characteristics at diagnosis of DLBCL: diagnosis of DM from medical records of previous outpatient visit or hospitalization (based on the International Statistical Classification of Diseases and Related Health Problems, 10th revision (ICD-10) code E10, E11 and E14 ${ }^{13}$ or antidiabetic prescriptions); fasting plasma glucose (FPG) level $\geq 7.0 \mathrm{mmol} / \mathrm{l}(126 \mathrm{mg} / \mathrm{dl})$ at first hospital admission for DLBCL before administration of prednisone. Diabetes newly identified during the DLBCL follow-up period was ignored. Prediabetes was defined as having medical histories of impaired fasting glucose (IFG) or impaired glucose tolerance (IGT) (ICD-10 code $\mathrm{R} 73.0)$ or $\mathrm{FPG} \geq 6.1 \mathrm{mmol} / 1(110 \mathrm{mg} / \mathrm{dl})$ and $<7.0 \mathrm{mmol} / 1$ $(126 \mathrm{mg} / \mathrm{dl})$ at DLBCL diagnosis. Diabetes, IFG and IGT were diagnosed according to the criteria established by the WHO. Diabetic duration calculated from the earliest applicable diagnosis of DM to the first DLBCL admission and antidiabetic treatments at enrollment were also collected from medical records and hospital registries.

FPG results were accessible from the hospital-based laboratorial service for all patients. Venous blood samples were collected between 7:00 am and 9:00 am after overnight fasting on the second day after the first admission. Within $2 \mathrm{~h}$ after blood sample collection, plasma glucose level was measured on an automatic enzymatic analyzer (Beckman Coulter, Brea, CA, USA) by means of glucose oxidase or hexokinase method under a stringent quality control mechanism.

\section{Follow-up and outcome measures}

The follow-up events included progression-free survival (PFS) and cancer-specific survival (CSS). PFS was defined as the date of initial diagnosis to the date of disease progression or death caused by lymphoma or treatment toxicity. Disease progression was defined and evaluated according to nodal masses (appearance of a new lesion(s) $>1.5 \mathrm{~cm}$ in any axis, $\geq 50 \%$ increase in sum of the product of the diameters (SPD) of more than one node, or $\geq 50 \%$ increase in longest diameter of a previously identified node $>1 \mathrm{~cm}$ in short axis, lesions positron emission tomography (PET) positive if fluorodeoxyglucose (FDG)-avid lymphoma or PET positive prior to therapy), spleen and liver ( $>50 \%$ increase from nadir in the SPD of any previous lesions) and bone marrow (new or recurrent involvement). ${ }^{12}$ For the accuracy of the standardized uptake value (SUV) measurement, the patient's blood glucose level was required to be controlled $<150 \mathrm{mg} / \mathrm{dL}$ before receiving intravenous ${ }^{18} \mathrm{~F}-\mathrm{FDG}$ injections, otherwise rescheduling the PET-CT. Most cases of disease progression which were accessible by biopsy considering the location and operational risk were further pathologically confirmed. CSS was calculated as the interval between diagnosis and DLBCL-specific death or end of the follow-up (June 2017). Cause of death coded as C83.3 based on ICD-10 was classified as DLBCL-specific death. ${ }^{13}$ Eleven deaths resulting from other causes, including four pneumonia (ICD-10 code J12.9 and J15.9), three lung cancers (ICD-10 code C34.9), three ischemic heart diseases (ICD-10 code I25.9) and one stroke (ICD-10 code I64) were excluded from the analyses. The follow-up included clinical and laboratorial checkups every 3 months for the first year and every 6 months from the 2 nd to the 5 th years at outpatient department. The patients were also required to be evaluated as soon as possible when having diseaserelated symptoms or signs of organ involvement. Specially, the examinations consisted of physical 


\begin{tabular}{|c|c|c|c|c|c|c|c|c|c|c|c|c|c|c|}
\hline \multirow{4}{*}{ 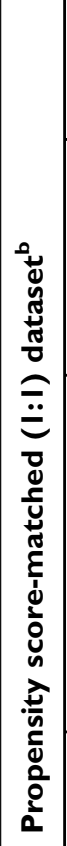 } & $\frac{\stackrel{0}{\Xi}}{\sum_{1}^{\pi}}$ & @ọ & ¿ & $\hat{0}_{0}^{m}$ & : & $\underset{\substack{N \\
m \\
0}}{0}$ & io & $\underset{i}{\text { N}}$ & $\stackrel{\infty}{\infty}_{0}^{\infty}$ & 总 & $\frac{0}{\pi}$ & $\frac{\hat{a}}{\alpha}$ & 啇 & 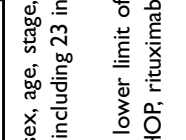 \\
\hline & 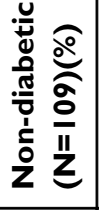 & 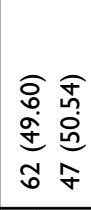 & 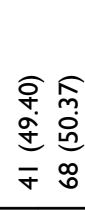 & 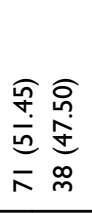 & 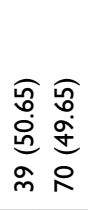 & 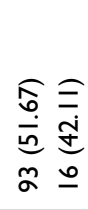 & 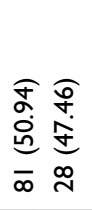 & 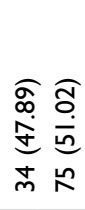 & 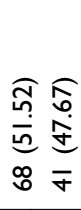 & 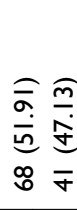 & 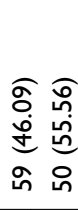 & 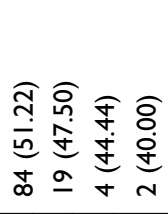 & 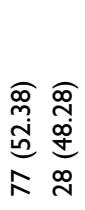 & 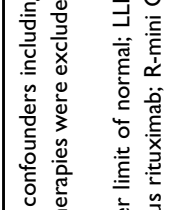 \\
\hline & 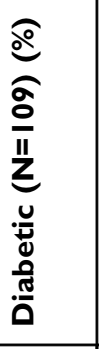 & 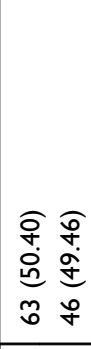 & 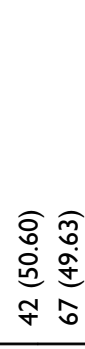 & 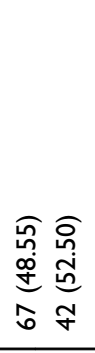 & 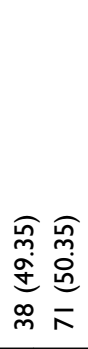 & 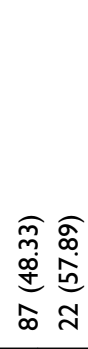 & 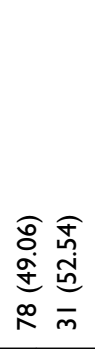 & 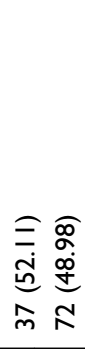 & 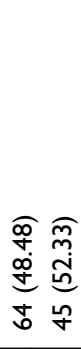 & 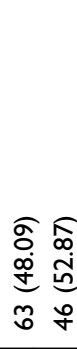 & 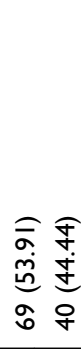 & 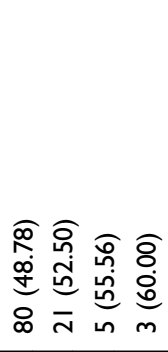 & 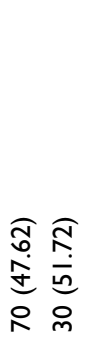 & 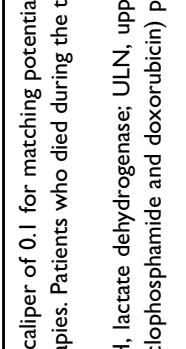 \\
\hline & 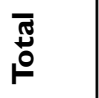 & $\stackrel{\sim}{\cong} \approx$ & $\stackrel{\infty}{\infty} \stackrel{\underline{m}}{\underline{n}}$ & $\stackrel{\infty}{=} \infty$ & 尺五 & $\stackrel{\infty}{\infty} \underset{m}{\infty}$ & 은 & $\bar{r}$ 主 & $\stackrel{\simeq}{2}$ & $\overline{\underline{m}} \hat{\infty}$ & $\stackrel{\text { đ̊ }}{\text { \& }}$ & to 8 a n & 主 & $\ddot{\overline{\bar{\theta}}}$ \\
\hline \multirow{4}{*}{ 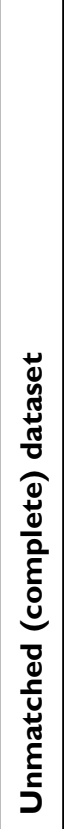 } & $\frac{0}{\frac{0}{\pi N}}$ & 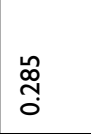 & $\overline{8}$ & $\stackrel{0}{\circ}$ & 음 & ồ & î & 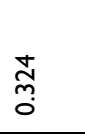 & $\begin{array}{l}\text { Oे } \\
\text { फ़้ }\end{array}$ & $\frac{\infty}{0}$ & 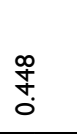 & $\begin{array}{l}\text { న్ } \\
\text { o } \\
0\end{array}$ & $\frac{\nabla}{m}$ & 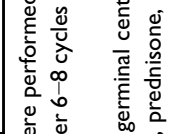 \\
\hline & 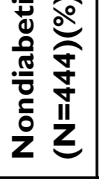 & 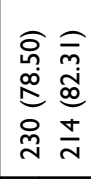 & 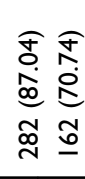 & 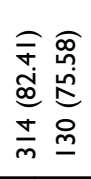 & 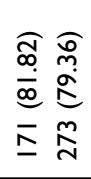 & 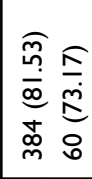 & 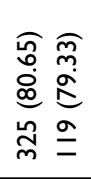 & 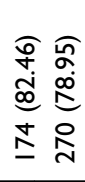 & 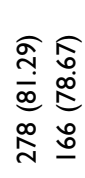 & 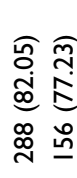 & 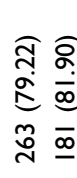 & 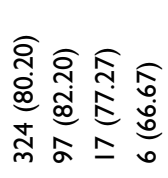 & 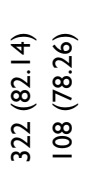 & 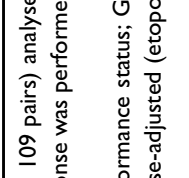 \\
\hline & 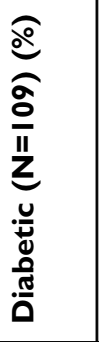 & 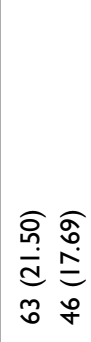 & 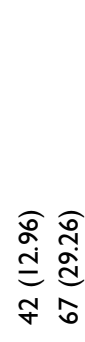 & 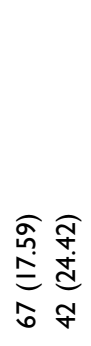 & 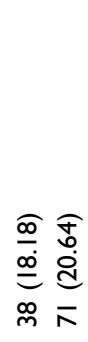 & 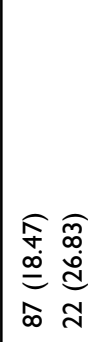 & 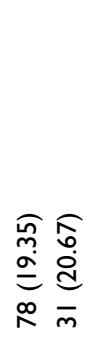 & 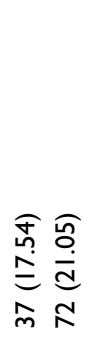 & 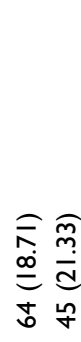 & 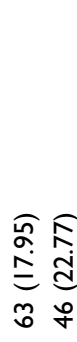 & 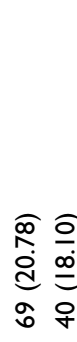 & 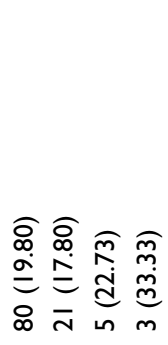 & 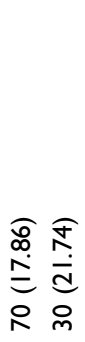 & 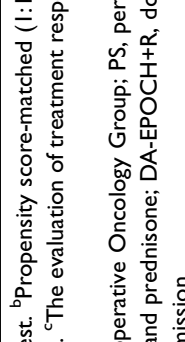 \\
\hline & 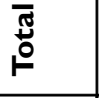 & స̃ : & ષ્ల స్ & $\bar{\infty} \underline{m}$ & 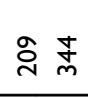 & $\bar{F} \infty$ & 웅 오 & $\overline{\bar{N}} \stackrel{f}{m}$ & $\overline{\mathrm{m}} \overline{\bar{n}}$ & लू & $\tilde{m} \overline{\text { ก }}$ & $\underset{+}{+} \stackrel{\infty}{=}$ ๙ & $\stackrel{\sim}{\tilde{m}} \stackrel{\infty}{=}$ & $\dot{0}$ \\
\hline \multirow[b]{2}{*}{$\frac{\pi}{5}$} & & $\frac{\frac{0}{\pi}}{\Sigma} \frac{\stackrel{0}{\pi}}{\Sigma}$ & 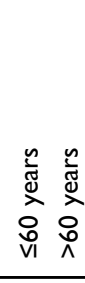 & $\begin{array}{ll}1 & 1 \\
0 & m \\
\end{array}$ & $\overline{\bar{I}} \stackrel{\geq}{\equiv}$ & $\begin{array}{ll}1 \\
0 & 1 \\
\end{array}$ & $\overline{\mathrm{v}} \bar{\wedge}$ & 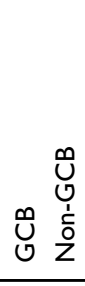 & 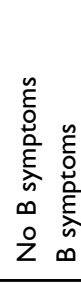 & 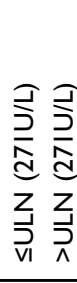 & 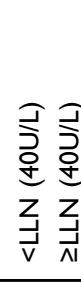 & 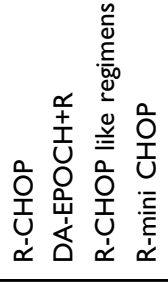 & 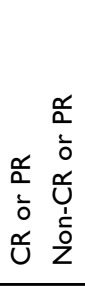 & 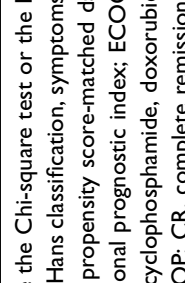 \\
\hline & & $\begin{array}{l}\bar{d} \\
\bar{v} \\
\bar{\Xi} \\
心 \\
\end{array}$ & 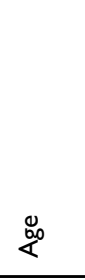 & $\overline{\underline{ }}$ & 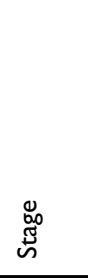 & \begin{tabular}{|l} 
n \\
un \\
0 \\
$u$ \\
\end{tabular} & 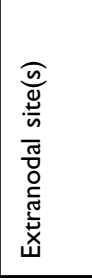 & 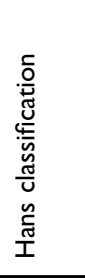 & $\underline{\mathrm{g}}$ & $\stackrel{I}{د}$ & 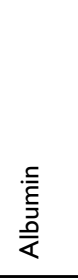 & 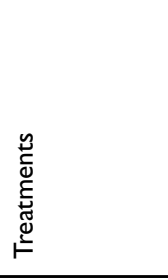 & 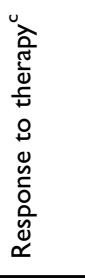 & 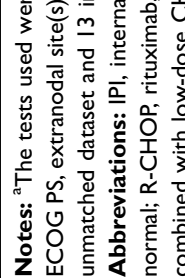 \\
\hline
\end{tabular}


examination, a panel of blood tests, enhancement CT or PET-CT and bone marrow assessment if necessary. The medical staff in our center would contact the patients or their families for the reminding of scheduled follow-up checkups. Diabetic patients and nondiabetics were treated unbiasedly with uniformity of reassessment. For those who survived $>5$ years, the follow-up and mortality data were carefully retrieved from hospital records, death certificates in local disease control center or by interviewing (directly or by telephone) the patients, their families and personal physicians annually. The follow-up data were available for 553 patients finally enrolled, while two patients lost to follow-up were excluded from the study population.

\section{Statistical analyses}

All statistical analyses were performed using SPSS 23.0 (SPSS, Chicago, IL, USA), Graphpad Prism 6.01 (La Jolla, CA, USA) and R software 3.2 .5 (http://www.r-project.org/) with MatchIt packages. Categorical variables were shown in percentage (\%) and compared by the Chi-square test or the Fisher's exact test. Continuous variables were displayed as mean \pm standard deviation and determined as to whether the two populations were normally distributed using the Kolmogorov-Smirnov test or the Shapiro-Wilk test, and whether they had homogeneity of variances using the Levene's test. For data following normal distribution and having homogeneity of variances, results were compared by the Student's $t$-test. While for data following non-normal distribution or having heterogeneity of variances, the Mann-Whitney U test or the Kruskal-Wallis test was applied. Kaplan-Meier method was used to establish survival curves. The log-rank test was performed in subgroup analyses for each stratum investigating the interaction between clinical parameters and DM, and also in pairwise comparisons by pairwise over strata evaluating the difference between every two specific groups. Multivariate Cox regression analyses screened the independent prognostic factors for PFS and CSS, and variance inflation factor (VIF) was calculated to rule out multicollinearity between the included parameters. PSM analyses, using the 1:1 nearest neighbor technique with a small caliper of 0.1 were performed. Factors including sex, age, stage, ECOG PS, extranodal site(s), Hans classification, symptoms and LDH level were balanced to re-evaluate univariate and multivariate analyses in the matched couples. Receiver-operator characteristic curves (ROCs) and the corresponding areas under the curve (AUC) assessed the predictive accuracy of IPI and DM. The difference of AUCs was tested by a nonparametric approach developed by DeLong et $\mathrm{al}^{14}$. Difference was considered significant with a two-sided $p$ value $<0.05$.

\section{Results}

\section{Patients' clinical characteristics in relation to diabetes}

Five hundred and fifty-three newly diagnosed DLBCL subjects whose treatments included rituximab were retrospectively recruited. In total, 109 (19.71\%) patients had preexisting DM, with 106 patients having a medical history of DM. Elevated FPG ( $\geq 7.0 \mathrm{mmol} / \mathrm{l})$ was found in the other 3 patients at DLBCL diagnosis. Additionally, 43 (7.78\%) patients had prediabetes, including 10 patients having a medical history of IFG or IGT, and the other 33 whose FPG level $\geq 6.1 \mathrm{mmol} / 1$ and $<7.0 \mathrm{mmol} / 1$ at enrollment. The mean FPG levels for diabetes and prediabetes were $7.235 \pm 2.115 \mathrm{mmol} / 1$ and $6.501 \pm 0.247 \mathrm{mmol} / 1$, respectively. The median diabetic duration was 48 months (range, 0-360 months).

The baseline characteristics according to diabetic status are summarized in Table 1. In the complete dataset, DLBCL patients whose age $>60$ years were more likely to have comorbid DM $(p<0.001)$. However, only a tendency toward significance was identified concerning IPI and ECOG PS that diabetic patients were more inclined to have high IPI and poor ECOG PS ( $p=0.065$ and $p=0.097$, respectively). Moreover, no significant difference was detected in the distribution of DLBCL treatments $(p=0.692)$ and response to therapy $(p=0.314)$, and thus diabetic and nondiabetic patients received relatively comparable treatments.

To balance the characteristics between diabetics and nondiabetics, PSM analyses with 1:1 ratio were applied to minimize the differences in potential confounders including sex, age, stage, ECOG PS, extranodal site(s), Hans classification, symptoms and LDH level. After matching, the mean propensity scores for diabetic and nondiabetic groups were $0.504 \pm 0.048$ and $0.496 \pm 0.042$ $(p=0.313)$. These clinicopathological parameters were adequately balanced and evenly distributed in the propensitymatched dataset as shown in Table 1 (all $p>0.2$ ).

\section{Prognostic value of preexisting DM in DLBCL}

The last follow-up results of all 553 patients enrolled in our study were obtained in June 2017 with a median 
follow-up of 43 months (range, 7-114 months), during which 127 (22.97\%) patients died, and 192 (34.72\%) patients experienced disease progression. Event rates of PFS and CSS in subgroups stratified by different clinical parameters are displayed in Table S1.

The median survival time of the whole cohort was not reached for both PFS (range, 0-113 months) and CSS (range, 1-114 months) (Table S2). As for diabetes, a significant difference in PFS was identified, with median PFS of 56 months (range, 1-91 months) for diabetic group, while not reached (range, $0-113$ months) for nondiabetics $(p=0.001)$. Worse CSS was also observed in patients with DM $(p<0.001)$. Although the median CSS was not reached for both groups, the 5-year CSS rate of diabetics (50.8\%) (range, 1-91 months) was evidently lower compared with nondiabetics (77.8\%) (range, 2-114 months) (Figure 1A and B).

Table 2 indicates the Cox regression analyses of prognostic factors for PFS and CSS (VIF $<10$ for both PFS and $\mathrm{CSS})$. All the variables, regardless of significance in univariate analyses, further entered multivariate analyses to

\section{A Unmatched (complete) dataset}

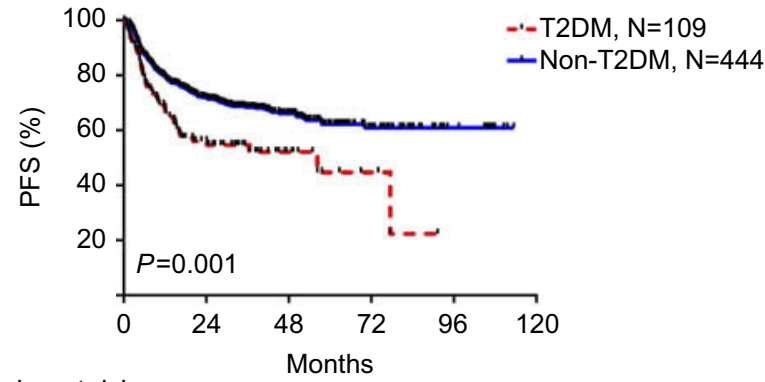

Number at risk

$\begin{array}{lllllll}\text { T2DM } & 109 & 64 & 62 & 61 & 60 & 60\end{array}$

$\begin{array}{lllllll}\text { Non-T2DM } & 444 & 324 & 308 & 301 & 301 & 301\end{array}$

\section{Propensity score-matched (1:1) dataset}

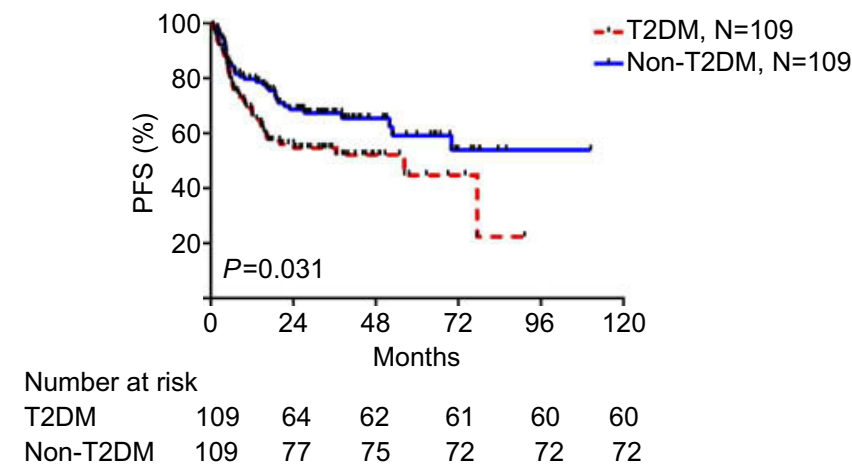

avoid confounding effect. For PFS of the complete cohort, five variables including age ( $>60$ years) $(\mathrm{HR}=1.426 ; 95 \%$ CI: $1.058-1.920 ; p=0.020$ ), advanced stage (III-IV) $(\mathrm{HR}=2.158 ; 95 \% \mathrm{CI}: 1.437-3.241 ; p<0.001)$, Hans classification of non-GCB (HR=1.666; 95\% CI: 1.208-2.298; $p=0.002), \mathrm{LDH}$ level $(>\mathrm{ULN})(\mathrm{HR}=2.041 ; 95 \% \mathrm{CI}: 1.497$ $-2.782 ; p<0.001)$ and diabetic $(\mathrm{HR}=1.452 ; 95 \% \mathrm{CI}: 1.033$ $-2.039 ; p=0.032$ ) remained significant. For CSS, six variables were selected: age ( $>60$ years $)(\mathrm{HR}=1.484 ; 95 \% \mathrm{CI}$ : 1.027-2.143; $\quad p=0.036$ ), advanced stage (III-IV) $(\mathrm{HR}=2.342 ; 95 \% \mathrm{CI}: 1.390-3.946 ; p=0.001)$, ECOG PS (2-4) $(\mathrm{HR}=1.885 ; 95 \% \mathrm{CI}: 1.241-2.861 ; p=0.003)$, Hans classification of non-GCB $(\mathrm{HR}=1.646 ; 95 \% \mathrm{CI}: 1.106$ $-2.451 ; p=0.014), \mathrm{LDH}$ level $(>\mathrm{ULN})(\mathrm{HR}=2.157 ; 95 \%$ CI: $1.463-3.181 ; p<0.001)$ and diabetic $(\mathrm{HR}=2.267 ; 95 \%$ CI: $1.542-3.334 ; p<0.001)$. Consequently, DM was an independent risk predictor for both PFS and CSS.

Results observed in the complete cohort were corroborated using the PSM dataset. As exhibited in KaplanMeier survival curves for the matched groups (Figure 1C

\section{B Unmatched (complete) dataset}

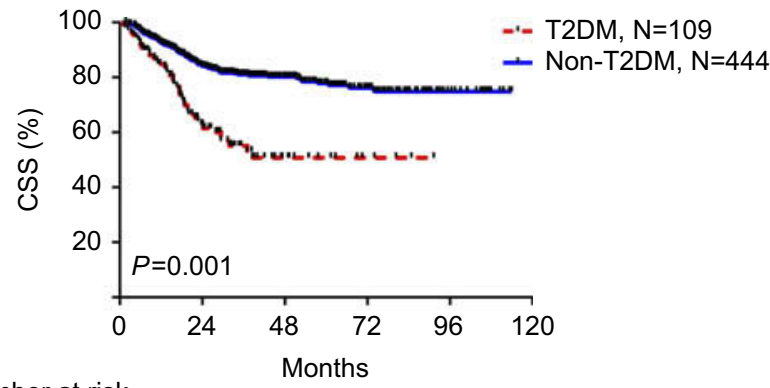

Number at risk

$\begin{array}{lllllll}\text { T2DM } & 109 & 73 & 66 & 66 & 66 & 66\end{array}$

Non-T2DM $444 \quad 379 \quad 367 \quad 361 \quad 360 \quad 360$

\section{Propensity score-matched (1:1) dataset}

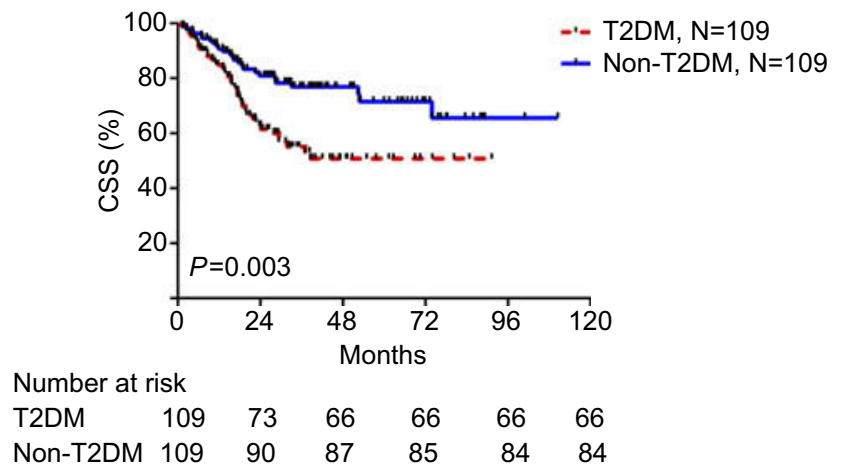

Figure I Kaplan-Meier curves of PFS and CSS stratified by diabetic status before and after propensity matching. (A) PFS in unmatched (complete) dataset.(B) CSS in unmatched (complete) dataset. (C) PFS in propensity score-matched (I:I) dataset. (D) CSS in propensity score-matched (I:I) dataset.

Abbreviations: PFS, progression-free survival; CSS, cancer-specific survival; DM, diabetes mellitus. 


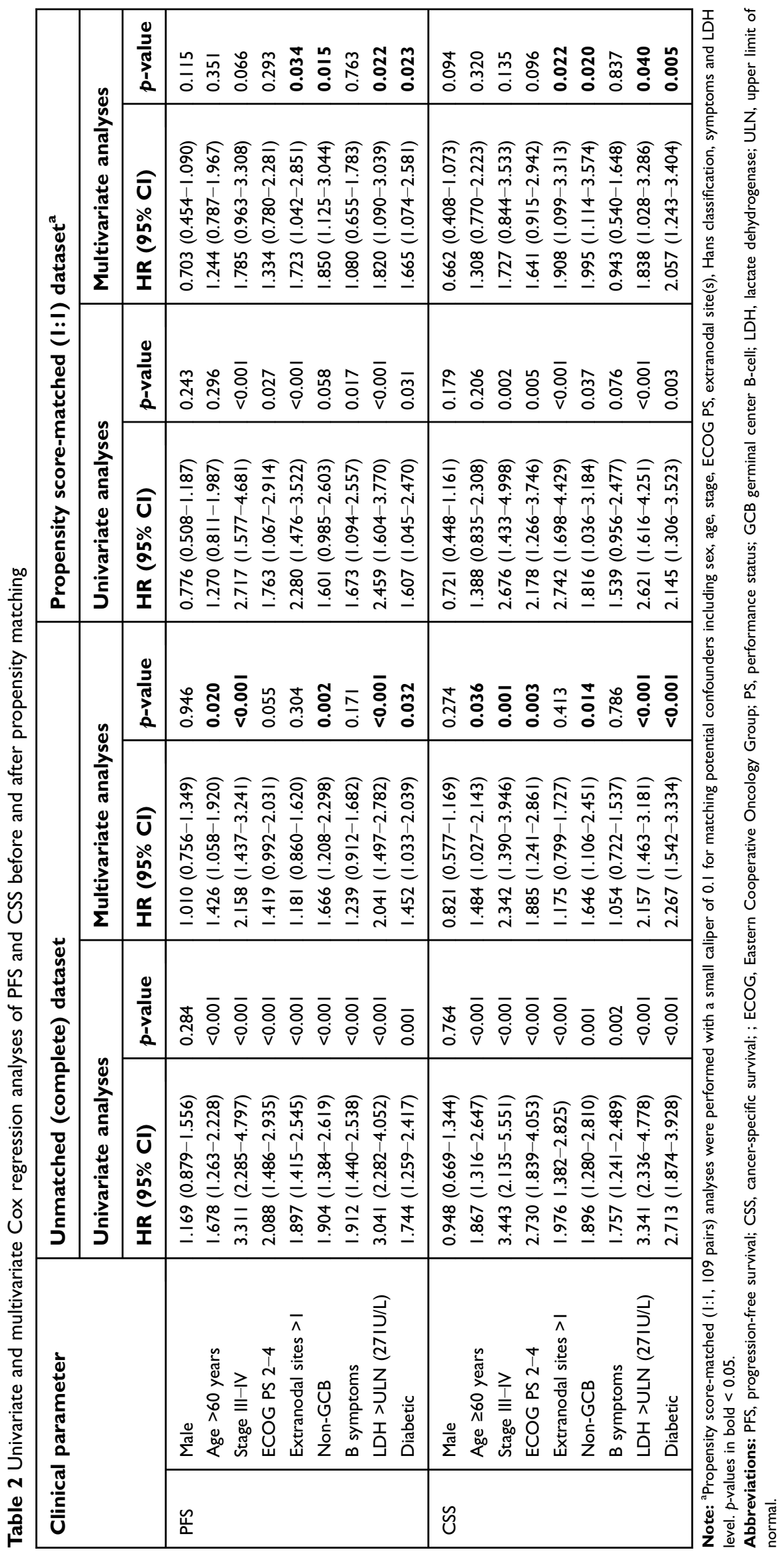


and D), patients with DM demonstrated significantly poorer PFS $(p=0.031)$ and CSS $(p=0.003)$ compared with nondiabetics. Multivariate Cox regression analyses after PSM showed similar results that DM still remained as an independent prognostic factor for both $\mathrm{PFS}(\mathrm{HR}=1.665$; 95\% CI: $1.074-2.581 ; p=0.023)$ and CSS $(\mathrm{HR}=2.057$; 95\% CI: $1.243-3.404 ; p=0.005$ ).

Owing to the fact that excluding information from future events would generate selection bias, we analyzed the association between DM and all-cause mortality by censoring individuals at the time of death due to other causes rather than excluding them. Univariate and multivariate Cox regression analyses of PFS and overall survival (OS) were conducted in 564 patients including the 11 who died of other causes (Figure S2 and Table S3). DM was an independent factor correlated with worse PFS and OS both in the complete (HR=1.409; 95\% CI: 1.012 $-1.961 ; p=0.042$ for PFS and HR=2.077; 95\% CI: 1.432 $-3.013 ; p<0.001$ for CSS) and PSM datasets (HR=1.769; 95\% CI: $1.144-2.735 ; p=0.010$ for PFS and $\mathrm{HR}=2.134$; 95\% CI: $1.294-3.520 ; p=0.003$ for CSS).

Cox regression analyses for PFS and CSS were also performed including chemoimmunotherapies received (Table S4). After adjusting for confounders including the treatment type (R-CHOP, DA-EPOCH+R, R-CHOP like regimens and R-mini $\mathrm{CHOP}$ ), DM was still significantly associated with unfavorable PFS and CSS both in the complete $(\mathrm{HR}=1.457 ; 95 \% \mathrm{CI}: 1.037-2.047 ; p=0.030$ for PFS and $\mathrm{HR}=2.258 ; 95 \% \mathrm{CI}: 1.535-3.324 ; p<0.001$ for CSS) and PSM datasets (HR=1.672; 95\% CI: 1.078 -2.592; $p=0.022$ for PFS and HR=2.052; 95\% CI: 1.239 $-3.397 ; p=0.005$ for CSS).

\section{Subgroup analyses of preexisting DM in DLBCL}

The results of subgroup analyses are shown in Table 3 (test for interaction: $p<0.05$ for all subgroups). After PSM, patients with DM in low-risk grade (IPI 0-2) had evidently poorer PFS $(p=0.011)$ and CSS $(p<0.001)$ compared with nondiabetics. Whereas in high-risk grade (IPI 3-5), no significance was identified between diabetic and nondiabetic DLBCL patients for both PFS $(p=0.507)$ and CSS $(p=0.370)$. Interestingly, similar results were noticed in subgroups stratified by age, stage, ECOG PS, extranodal sites involvement, Hans classification, symptoms and LDH level. Significant differences in PFS between diabetics and nondiabetics were shown in patients with younger age ( $\leq 60$ years), earlier stage (I-II), no B symptoms and lower LDH concentration $(\leq \mathrm{ULN})$. While for OS, diabetic patients demonstrated significant inferior survival to nondiabetics in population with younger age $(\leq 60$ years), better ECOG PS ( $0-1)$, fewer extranodal sites $(\leq 1)$, Hans classification of GCB, no B symptoms and lower LDH concentration $(\leq \mathrm{ULN})$. These findings might indicate that $\mathrm{DM}$ as a valuable prognostic factor could further stratify the survival outcome of low-risk DLBCL patients.

\section{Prediabetes, diabetic duration, $\mathrm{HbAlc}$ and treatments in relation to DLBCL prognosis}

Four hundred and forty-four nondiabetic patients were categorized into prediabetics (43 cases) and patients having no tendency toward DM (401 cases). As observed in Figure $2 \mathrm{~A}$ and $\mathrm{B}$, significant overall differences in PFS $(p<0.001)$ and CSS $(p<0.001)$ were identified among the three subgroups (log-rank test across all groups). Pairwise comparisons of every specific two groups exhibited that prediabetic patients were more inclined to have poorer PFS $(p=0.001)$ and CSS $(p=0.004)$ compared with those having no diabetic tendency. However, no significantly favorable survival outcome was detected in prediabetics compared with diabetics for both PFS $(p=0.732)$ and CSS $(p=0.277)$ (Table S5).

Diabetic duration was defined as the interval from the date of initial diagnosis as DM to the date of first DLBCL hospital admission. One hundred and nine diabetic patients were divided into four categories by quartiles (Q1 $=25 \%$, $\mathrm{Q} 2=50 \%, \mathrm{Q} 3=75 \%)$ of diabetic duration: $\geq 120$ months, $\geq 48$ and $<120$ months, $\geq 12$ and $<48$ months and $<12$ months. Three patients whose FPG $>7.0 \mathrm{mmol} / \mathrm{l}$ at enrollment were also diabetics, and their diabetic durations were calculated as 0 month. In Figure $2 \mathrm{C}$ and $\mathrm{D}$, longer diabetic duration was associated with worse PFS and CSS in DLBCL patients $(p<0.001$ for both PFS and CSS, log-rank test across all groups). Further comparisons by pairwise over strata showed diabetic patients with duration $<12$ months had evidently better prognosis than other subgroups (all $p \leq 0.001$ ) (Table S6).

Due to the retrospective nature of this study, test of HbA1c was only performed in 61 diabetic DLBCL cases. Diabetic patients with (61 cases) and without (48 cases) HbA1c result had no significant difference in the distribution of clinical characteristics (all $p>0.05$ ). Diabetic 


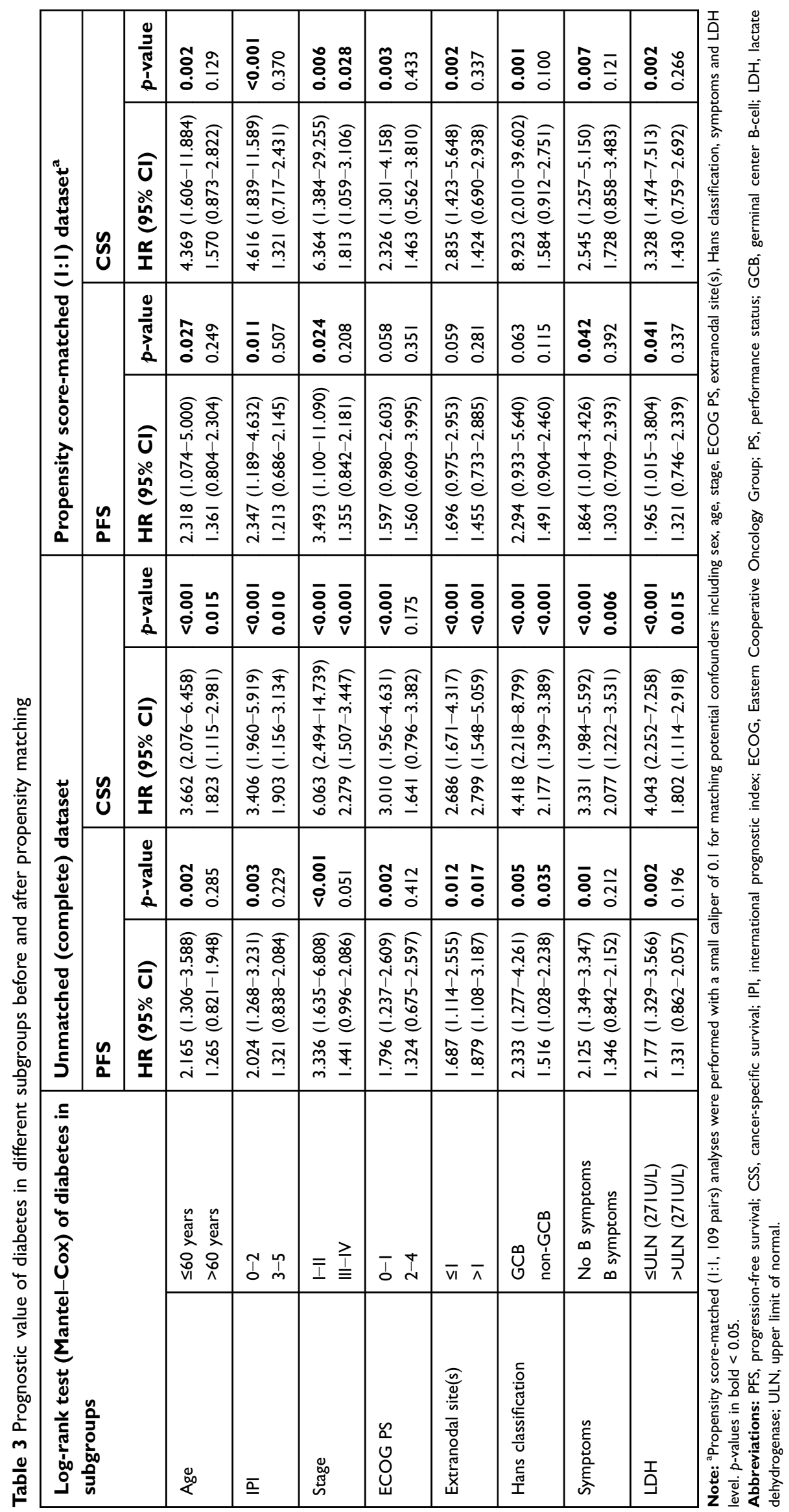




\section{A Different diabetic status}

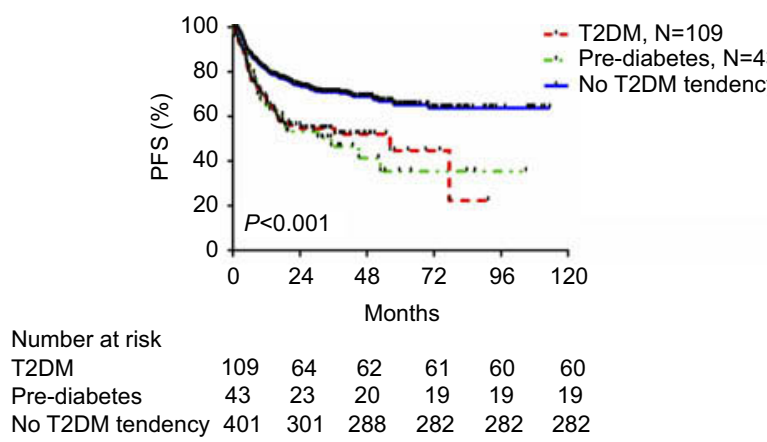

\section{Different diabetic durations}

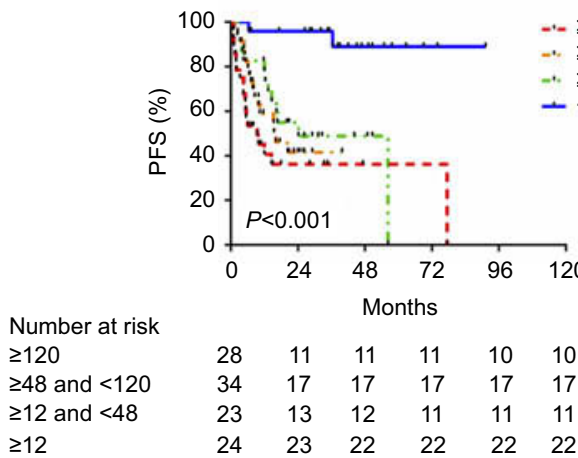

\section{E Different HbA1c levels}

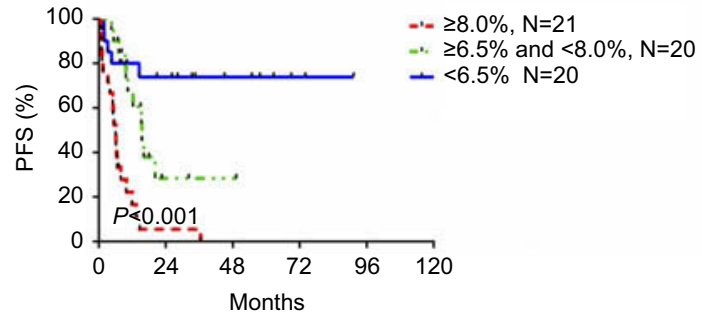

Number at risk

$\begin{array}{lllllll}\geq 8.0 \% & 21 & 2 & 1 & 1 & 1 & 1\end{array}$

$\begin{array}{lcccccc}\geq 6.5 \% \text { and }<8.0 \% & 20 & 9 & 9 & 9 & 9 & 9 \\ <6.5 \% & 20 & 15 & 15 & 15 & 15 & 15\end{array}$

\section{B Different diabetic status}

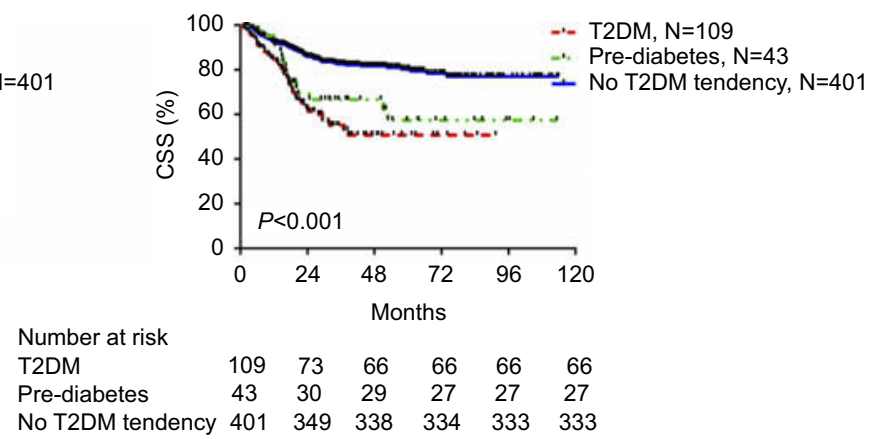

D Different diabetic durations

Figure 2 Prediabetes, diabetic duration and HbAlc level in relation to DLBCL survival. (A) PFS stratified by different diabetic status of T2DM, pre-diabetes and no T2DM tendency. (B) CSS stratified by different diabetic status of T2DM, pre-diabetes and no T2DM tendency. (C) PFS stratified by different diabetic durations. (D) CSS stratified by different diabetic durations. (E) PFS stratified by different HbAlc levels. (F) CSS stratified by different HbAlc levels.

Abbreviations: PFS, progression-free survival; CSS, cancer-specific survival; DM, diabetes mellitus; HbAlc, hemoglobin Alc; DLBCL, diffuse large B- cell lymphoma.

patients were subdivided into three groups according to their HbA1c levels: $\geq 8.0 \%, \geq 6.5 \%$ and $<8.0 \%$ and $<6.5 \%$. Figure $2 \mathrm{E}$ and $\mathrm{F}$ and pairwise comparisons presented that adequate glycemic control was associated with longer PFS and CSS in diabetic DLBCL patients (Table S7).

We also investigated the correlation between diabetic medications and prognosis of DLBCL. Pairwise comparisons exhibited that no significant difference was identified for both PFS and CSS between every two hypoglycemic treatments (oral antidiabetic drugs vs insulin; oral antidiabetic drugs vs nonmedication; insulin vs nonmedication). Further adjustments for other potential confounders including diabetic duration did not change the magnitude substantially (Table S8).

\section{DM together with IPI: a better prognostic index for DLBCL}

For the reason that DM remained as an independent prognostic factor for both PFS and CSS in multivariate analyses, introducing a novel PI which included IPI together with DM might 
A

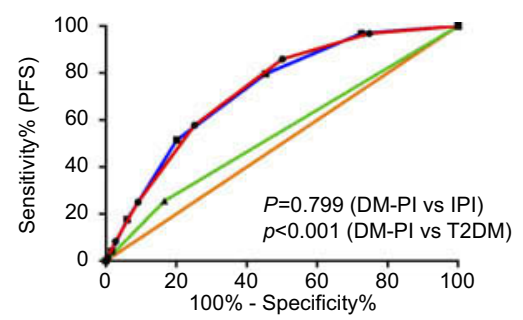

$\rightarrow$ DM-PI (IPI+T2DM) AUC: 0.731 SE: 0.021 95\%Cl: $0.692-0.768$

$\rightarrow$ IPI

$\because$ T2DM

- Reference

C

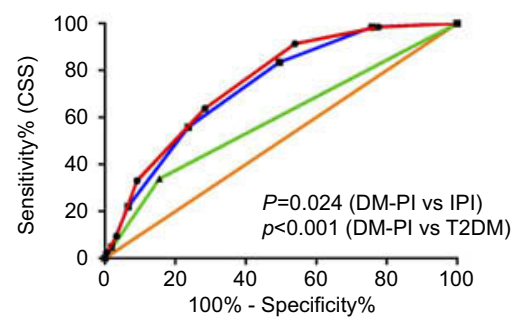

$\rightarrow$ DM-PI (IPI+T2DM)

$\rightarrow \mid \mathrm{PI}$

- T2DM

- Reference
B

Number at risk High risk $\begin{array}{llllll}81 & 35 & 33 & 33 & 33 & 33\end{array}$ $\begin{array}{lllllll}\text { Low risk } & 266 & 165 & 157 & 150 & 149 & 149 \\ & 206 & 188 & 180 & 179 & 179 & 179\end{array}$

Figure 3 DM together with IPI is a better prognostic index for DLBCL. (A) The AUC comparison between DM-PI, IPI and T2DM alone for PFS prediction. (B) Kaplan-Meier curves of PFS for three different DM-PI risk grades. (C) The AUC comparison between DM-PI, IPI and T2DM alone for CSS prediction. (D) Kaplan-Meier curves of CSS for three different DM-PI risk grades.

Abbreviations: PFS, progression-free survival; CSS, cancer-specific survival; DM, diabetes mellitus; DLBCL, diffuse large B-cell lymphoma; IPI, international prognostic index; DM-PI, prognostic index including diabetes mellitus; AUC, area under the curve.

provide better predictive accuracy than IPI alone. PI was calculated as the sum of IPI and one additional point for patient's diabetic status. Interestingly as shown in Figure 3A and C, PI exhibited evidently larger AUC and greater accuracy than IPI alone in CSS prediction ( 0.752 vs $0.732, p=0.024)$. To further validate that PI was a better index for CSS prediction, we divided the entire cohort into three risk grades: low-risk group (DM-PI 0-1), intermediate-risk group (DM-PI 2-3) and high-risk group (DM-PI 4-6). A significant overall difference in CSS can be observed from the three subgroups ( $p<0.001$, log-rank test across all groups) that DLBCL patients in highrisk grade demonstrated the poorest CSS and those in low-risk grade had the most favorable survival outcomes (Figure 3B and D). The 3-year and 5-year PFS and CSS of the complete dataset stratified by the IPI and the DM-PI are demonstrated in Table 4. The DM-PI both widened the definition of low-risk and high-risk patients for 3-year and 5-year CSS and maintained equivalent accuracy to the IPI in PFS estimation.

Table 4 PFS and CSS according to the IPI and the DM-PI in the complete dataset

\begin{tabular}{|l|l|l|l|l|}
\hline Risk group & IPI 3-year PFS (\%) & IPI 5-year PFS (\%) & IPI 3-year CSS (\%) & IPI 5-year CSS (\%) \\
\hline Low (0-I) & 85.2 & 83.9 & 92.8 & 91.5 \\
Intermediate (2-3) & 58.6 & 54.8 & 72.4 & 70.9 \\
High (4-5) & 39.3 & 39.3 & 51.8 & 50.0 \\
\hline Risk group & DM-PI 3-year PFS (\%) & DM-PI 5-year PFS (\%) & DM-PI 3 year-CSS (\%) & DM-PI 5-year CSS (\%) \\
\hline Low (0-I) & 88.3 & 86.9 & 96.1 & 95.1 \\
Intermediate (2-3) & 60.5 & 56.8 & 74.8 & 72.9 \\
High (4-6) & 40.7 & 40.7 & 49.4 & 48.1 \\
\hline
\end{tabular}

Abbreviations: PFS, progression-free survival; CSS, cancer-specific survival; IPI, international prognostic index; DM-PI, prognostic index including diabetes. 
Additionally, pairwise comparisons as displayed in Table S9 indicated evident difference in CSS between every two specific risk grades, which suggested that PI could accurately differentiate DLBCL patients into different risk grades for CSS prediction.

\section{Discussion}

To our knowledge, no previous study has focused on the correlation between DLBCL and DM, and this is the first article providing evidence that DM could serve as an independent risk factor for survival in patients with DLBCL.

Diabetes is associated with elevated risks in various malignancies, especially in gastric, pancreatic and hepatocellular cancers. Our study demonstrated that the prevalence of preexisting DM in DLBCL was 19.71\%, which was evidently higher in comparison with the results from a Chinese national study of diabetes $(9.70 \%)$, including representative samples of 46,239 adults. ${ }^{15}$ Tseng et al concluded DM was associated with high risk of developing NHL (OR=1.51; 95\% CI: $1.33-1.71)$ in Taiwan ${ }^{16}$ and Yang et al demonstrated similar results with HR of 2.00 (95\% CI: 1.32-3.03) in mainland China. ${ }^{17}$ Additionally, Lin et al reported that preexisting DM was an independent risk factor for the occurrence of $\mathrm{NHL}(\mathrm{OR}=1.88$; 95\% CI: 1.22-2.89), particularly for extranodal presentation, T-cell subtype and low-grade tumor. ${ }^{18}$ However, a multinational investigation, namely European Prospective Investigation into Cancer and Nutrition study, revealed a lack of association. ${ }^{19}$ This investigation did not separately analyze the incidence and mortality rate of NHL.

The pros and cons of PSM deserve mention and are listed as follows. Pros are: 1) equating groups at baseline especially in studies that do not use randomization; 2) accounted for "nuisance" factors that differ between the groups, so that any remaining difference is likely due to the variable of interest. Cons are: 1) difficult to include all the confounding covariates; 2) possibility of losing subjects depending on the original size of the pool of available people and the amount of overlap, further jeopardizing the results of the study; 3) many alternative methods (nearest neighbor, caliper matching, etc.) reflect that no single approach is ideal and each has limitations, thus sensitivity analyses are needed.

Our findings suggested that DM was associated with worse PFS and CSS both in the complete and propensitymatched cohorts, and it was an independent risk factor for both PFS and CSS. In subgroup analyses, DM was correlated with inferior survival only in patients with younger age ( $\leq 60$ years), lower IPI, no B symptoms and lower LDH concentration. The probable explanation for this phenomenon is that other strong prognostic factors such as older age, more advanced stage and higher IPI outweighed and covered up the effect of DM on prognosis. PFS and CSS of high-risk group may be greater influenced by lymphoma effect, and those of low-risk group may be more likely to be influenced by nonlymphoma comorbidities including DM. Accordingly, DM could be a valuable indicator improving the prognostic stratification of lowrisk DLBCL patients.

We also demonstrated that prediabetics were more likely to have inferior prognosis compared to patients with no diabetic tendency. It may imply that DLBCL patients with prediabetes should be given equal concerns as those with comorbid DM because they might share inferior survival outcomes. Additionally, patients with shorter diabetic duration $(<12$ months) and adequate glycemic control ( $\mathrm{HbA} 1 \mathrm{C}<6.5 \%)$ presented better survival. Given that patients who died of non-DLBCL-related conditions including diabetic complications were excluded from the study, the above findings could directly indicate the impact of DM on DLBCL-specific survival.

We noticed that DM together with IPI (DM-PI) had larger AUC compared with IPI alone in CSS prediction. Although statistically significant, the inclusion of DM only resulted in minor improvement. To interpret our results more cautiously, DM-PI was not intended to replace IPI in clinical practice, but diabetes should be well-assessed and managed in DLBCL patient care. Due to the retrospective nature and lack of validation cohort, our results remain to be replicated and confirmed in epidemiologic studies with larger samples, longer follow-up periods and full adjustments for covariates to test the proposed prognostic score.

As previously reported in epidemiological evidence, diabetic NHL patients had evidently worse survival after approximately 1 year of follow-up, and it was an accelerated factor for the risk of death from causes related to nonHodgkin's lymphoma. ${ }^{18}$ Another cohort study among Taiwanese population suggested diabetics were at an increased risk of NHL mortality $(\mathrm{HR}=1.028$; 95\% CI: 1.005-1.051). ${ }^{20}$ For other site-specific cancers, evidence was provided that preexisting diabetes was associated with poor disease-free survival (DFS) and overall survival (OS) in lung $(\mathrm{HR}=1.27 ; 95 \% \mathrm{CI}: 1.07-1.50),{ }^{21}$ breast $(\mathrm{HR}=1.97 ; 95 \% \mathrm{CI}: 1.45-2.68),{ }^{22}$ colorectal $(\mathrm{HR}=1.17$; 95\% CI: $1.09-1.25)^{23}$ and prostate cancer $(\mathrm{HR}=1.56$; $95 \% \mathrm{CI}: 1.03-2.36){ }^{24}$ 
However, the potential etiology role of DM in DLBCL development has not been investigated, and it is difficult to tease out a possible causal sequence between DM and DLBCL. It was postulated that these two diseases might share common pathways and risk factors in the early stage of development, such as immunodeficiency and obesity. ${ }^{25}$ DM is related to high oxidative stress, inflammatory status, and immune dysfunction which are implicated in the tumorigenesis of DLBCL. In preclinical experiments, a mouse DLBCL cell line with Chemokine (C-C motif) ligand 5 (CCL5) overexpression and knockdown subclones were subcutaneously injected into both BALB/c DM mice and normal mice. Zhang et al concluded that CCL5 could be one of the indispensable chemoattractant cytokines involved in DM with DLBCL, and high levels of CCL5 expression could accelerate the formation of DLBCL in DM mice. ${ }^{26}$ Another study in vivo demonstrated G13997A mitochondrial DNA could regulate diabetes development and lymphoma formation via the overproduction of reactive oxygen species (ROS) or lactate. ${ }^{27}$

In the current clinical practice of DLBCL, little attention was paid to controlling the progression of comorbid DM and its complication. The implications of our study are: 1) concerns should be given to patients with diabetes or prediabetes at first diagnosis of DLBCL to help predict life expectancy; (2) blood glucose level should be routinely monitored for diabetic patients, because hyperglycemia could cause prednsolone dosing attenuated, it should be actively controlled using effective antidiabetic agents.

The limitations of our study are illustrated as follows: the restriction within one institution; limited number of patients enrolled; inability to account for unmeasured confounders despite using PSM analyses (eg, different types of rituximab combination chemotherapies including $\mathrm{R}$ CHOP, DA-EPOCH+R, R-CHOP-ike regimes and R-mini CHOP; diabetes-related lifestyle) and the retrospective nature of this study with incomplete data on HbAlc. Owing to the fact that the informed consent was not restricted to this study and the research design was not established before the patients' enrollment, we still consider it as a retrospective one.

Our study concluded that DLBCL patients with preexisting DM had evident worse PFS and CSS than those without $\mathrm{DM}$ in rituximab era, and it was an independent risk factor for PFS and CSS both in the complete and PSM datasets. Prediabetics also demonstrated inferior prognostic outcomes compared to patients with no diabetic tendency. Adding the criterion of DM improved the prognostic capacity and risk stratification of IPI for CSS prediction. Further multi-central and multi-racial prospective studies with improved control of confounders are needed to confirm these findings.

\section{Acknowledgments}

We are grateful to all the study participants, patients and their family members for their contributions and supports. This study was supported by National Natural Science Foundation of China $(81370657,81470328,81600130$, 81770166, 81720108002), Jiangsu Province's Medical Elite Programme (ZDRCA2016022), Project of National Key Clinical Specialty, National Science \& Technology Pillar Program (2014BAI09B12), Jiangsu Provincial Special Program of Medical Science (BL2014086 and BE2017751) and National Science and Technology Major Project (2017ZX09304032).

\section{Disclosure}

The authors report no conflicts of interest in this work.

\section{References}

1. Dyal HK, Aguilar M, Bartos G, et al. Diabetes mellitus increases risk of hepatocellular carcinoma in chronic hepatitis c virus patients: a systematic review. Dig Dis Sci. 2016;61(2):636-645. doi:10.1007/ s10620-015-3983-3

2. Chari ST, Leibson CL, Rabe KG, et al. Pancreatic cancer-associated diabetes mellitus: prevalence and temporal association with diagnosis of cancer. Gastroenterology. 2008;134(1):95-101. doi:10.1053/j. gastro.2007.10.040

3. Luo W, Cao Y, Liao C, et al. Diabetes mellitus and the incidence and mortality of colorectal cancer: a meta-analysis of 24 cohort studies. Colorectal Dis. 2012;14(11):1307-1312. doi:10.1111/j.14631318.2012.02875.x

4. Zhou Y, Zhang X, Gu C, et al. Influence of diabetes mellitus on mortality in breast cancer patients. ANZ J Surg. 2015;85(12):972978. doi:10.1111/ans.12877

5. Mitri J, Castillo J, Pittas AG. Diabetes and risk of non-hodgkin's lymphoma: a meta-analysis of observational studies. Diabetes Care. 2008;31(12):2391-2397. doi:10.2337/dc08-1034

6. Castillo JJ, Mull N, Reagan JL, et al. Increased incidence of nonHodgkin lymphoma, leukemia, and myeloma in patients with diabetes mellitus type 2: a meta-analysis of observational studies. Blood. 2012;119(21):4845-4850. doi:10.1182/blood-2011-06-362830

7. Chao C, Page JH. Type 2 diabetes mellitus and risk of non-Hodgkin lymphoma: a systematic review and meta-analysis. Am J Epidemiol. 2008;168(5):471-480. doi:10.1093/aje/kwn160

8. Martelli M, Ferreri AJ, Agostinelli C, et al. Diffuse large b-cell lymphoma. Crit Rev Oncol Hematol. 2013;87(2):146-171. doi:10.1016/j.critrevonc.2012.12.009

9. Tilly H, Gomes Da Silva M, Vitolo U, et al. Diffuse large b-cell lymphoma (dlbcl): esmo clinical practice guidelines for diagnosis, treatment and follow-up. Ann Oncol. 2015;26(Suppl 5):v116-v125. doi:10.1093/annonc/mdv304

10. Friedberg JW. Relapsed/refractory diffuse large b-cell lymphoma. Hematology Am Soc Hematol Educ Program. 2011;2011:498-505. doi:10.1182/asheducation-2011.1.498 
11. Goto N, Tsurumi H, Kasahara S, et al. Serum interleukin-18 level is associated with the outcome of patients with diffuse large bcell lymphoma treated with chop or r-chop regimens. Eur $J$ Haematol. 2011;87(3):217-227. doi:10.1111/j.1600-0609.2011. 01649.x

12. Cheson BD, Pfistner B, Juweid ME, et al. Revised response criteria for malignant lymphoma. J Clin Oncol. 2007;25(5):579-586. doi: $10.1200 / \mathrm{JCO} .2006 .09 .2403$

13. National Center for Classification in Health. The International Statistical Classification of Diseases and Related Health Problems, Tenth Revision, Australian Modification (Icd-10, Am). 3rd ed. Sydney; 2012.

14. DeLong ER, DeLong DM, Clarke-Pearson DL. Comparing the areas under two or more correlated receiver operating characteristic curves: a nonparametric approach. Biometrics. 1988;44(3):837-845.

15. Yang W, Lu J, Weng J, et al. Prevalence of diabetes among men and women in china. $N$ Engl $J$ Med. 2010;362(12):1090-1101. doi:10.1056/NEJMoa0908292

16. Tseng $\mathrm{CH}$. Diabetes and non-hodgkin's lymphoma: analyses of prevalence and annual incidence in 2005 using the national health insurance database in taiwan. Ann Oncol. 2012;23(1):153-158. doi:10.1093/annonc/mdr334

17. Yang WS, Li HL, Xu HL, et al. Type 2 diabetes and the risk of nonhodgkin's lymphoma: a report from two population-based cohort studies in china. Eur $J$ Cancer Prev. 2016;25(2):149-154. doi:10.1097/CEJ.0000000000000150

18. Lin SY, Hsieh MS, Chen LS, et al. Diabetes mellitus associated with the occurrence and prognosis of non-hodgkin's lymphoma. Eur $J$ Cancer Prev. 2007;16(5):471-478. doi:10.1097/01.cej.0000236253. 93984.8f
19. Khan AE, Gallo V, Linseisen J, et al. Diabetes and the risk of nonhodgkin's lymphoma and multiple myeloma in the european prospective investigation into cancer and nutrition. Haematologica. 2008;93 (6):842-850. doi:10.3324/haematol.12297

20. Tseng $\mathrm{CH}$. Diabetes, insulin use, and non-Hodgkin lymphoma mortality in taiwan. Metabolism. 2012;61(7):1003-1009. doi:10.1016/j. metabol.2011.11.015

21. Luo J, Hendryx M, Qi L, et al. Pre-existing diabetes and lung cancer prognosis. Br J Cancer. 2016;115(1):76-79. doi:10.1038/bjc.2016.141

22. Mu L, Zhu N, Zhang J, et al. Type 2 diabetes, insulin treatment and prognosis of breast cancer. Diabetes Metab Res Rev. 2016;33:e2823.

23. Mills KT, Bellows CF, Hoffman AE, Kelly TN, Gagliardi G. Diabetes mellitus and colorectal cancer prognosis: a meta-analysis. Dis Colon Rectum. 2013;56(11):1304-1319. doi:10.1097/ DCR.0b013e3182a479f9

24. Polesel J, Gini A, Dal Maso L, et al. The impact of diabetes and other metabolic disorders on prostate cancer prognosis. $J$ Diabetes Complications. 2016;30(4):591-596. doi:10.1016/j. jdiacomp.2016.02.008

25. Ekstrom-Smedby K. Epidemiology and etiology of non-Hodgkin lymphoma-a review. Acta Oncol. 2006;45(3):258-271. doi:10.1080/ 02841860500531682

26. Zhang J, Luo J, Liu F, et al. Diabetes mellitus potentiates diffuse large bcell lymphoma via high levels of cc15. Mol Med Rep. 2014;10 (3):1231-1236. doi:10.3892/mmr.2014.2341

27. Hashizume O, Shimizu A, Yokota M, et al. Specific mitochondrial DNA mutation in mice regulates diabetes and lymphoma development. Proc Natl Acad Sci U S A. 2012;109(26):10528-10533. doi:10.1073/pnas.1202367109 


\section{Supplementary materials}

Table SI Event rates of PFS and CSS in subgroups stratified by different clinical parameters

\begin{tabular}{|c|c|c|c|c|c|c|}
\hline \multicolumn{2}{|c|}{ Clinical parameters } & \multirow{4}{*}{$\begin{array}{l}\text { Total } \\
293 \\
260\end{array}$} & \multicolumn{2}{|l|}{ PFS } & \multicolumn{2}{|l|}{ CSS } \\
\hline & & & \multirow{3}{*}{$\begin{array}{l}\text { Event (N) } \\
109 \\
83\end{array}$} & \multirow{3}{*}{$\begin{array}{l}\text { Rate (\%) } \\
37.20 \\
31.92\end{array}$} & \multirow{3}{*}{$\begin{array}{l}\text { Event (N) } \\
67 \\
60\end{array}$} & \multirow{3}{*}{$\begin{array}{l}\text { Rate (\%) } \\
22.87 \\
23.08\end{array}$} \\
\hline Gender & Male & & & & & \\
\hline & Female & & & & & \\
\hline Age & $\leq 60$ years & 324 & 94 & 29.01 & 59 & $|8.2|$ \\
\hline & $>60$ years & 229 & 98 & 42.79 & 68 & 29.69 \\
\hline \multirow[t]{2}{*}{ IPI } & $0-2$ & 381 & 93 & 24.41 & 56 & 14.70 \\
\hline & $3-5$ & 172 & 99 & 57.56 & 71 & 41.28 \\
\hline \multirow[t]{2}{*}{ Stage } & $|-| I$ & 209 & 34 & 16.27 & 20 & 9.57 \\
\hline & III-IV & 344 & 158 & 45.93 & 107 & 31.10 \\
\hline \multirow[t]{2}{*}{ ECOG PS } & $0-1$ & 471 & 149 & 31.63 & 93 & 19.75 \\
\hline & $2-4$ & 82 & 43 & 52.44 & 34 & 41.46 \\
\hline \multirow[t]{2}{*}{ Extranodal site(s) } & $\leq 1$ & 403 & 121 & 30.02 & 78 & 19.35 \\
\hline & $>1$ & 150 & 71 & 47.33 & 49 & 32.67 \\
\hline \multirow[t]{2}{*}{ Hans classification } & $\mathrm{GCB}$ & 211 & 52 & 24.64 & 34 & 16.11 \\
\hline & Non-GCB & 342 & 140 & 40.94 & 93 & 27.19 \\
\hline \multirow[t]{2}{*}{ Symptoms } & No B symptoms & 342 & 95 & 27.78 & 63 & 18.42 \\
\hline & B symptoms & 211 & 97 & 45.97 & 64 & 30.33 \\
\hline \multirow[t]{2}{*}{$\mathrm{LDH}$} & $\leq$ ULN (27IU/L) & 351 & 82 & 23.36 & 49 & 13.96 \\
\hline & $>\operatorname{ULN}(27 I \mathrm{IU} / \mathrm{L})$ & 202 & 110 & 54.46 & 78 & 38.61 \\
\hline \multirow[t]{2}{*}{ Albumin } & $<$ LLN (40U/L) & 332 & 132 & 39.76 & 92 & $27.7 \mid$ \\
\hline & $\geq \operatorname{LLN}(40 \mathrm{U} / \mathrm{L})$ & 221 & 60 & 27.15 & 35 & 15.84 \\
\hline \multirow[t]{4}{*}{ Treatments } & $\mathrm{R}-\mathrm{CHOP}$ & 404 & 144 & 35.64 & 92 & 22.77 \\
\hline & $\mathrm{DA}-\mathrm{EPOCH}+\mathrm{R}$ & 118 & 39 & 33.05 & 28 & 23.73 \\
\hline & $\mathrm{R}-\mathrm{CHOP}$ like regimens & 22 & 6 & 27.27 & 6 & 27.27 \\
\hline & R-mini CHOP & 9 & 3 & 33.33 & I & 11.11 \\
\hline \multirow[t]{2}{*}{ Response to therapy ${ }^{\mathrm{a}}$} & $C R$ or $P R$ & 392 & 69 & 17.60 & 34 & 8.67 \\
\hline & Non-CR or PR & 138 & 100 & 72.46 & 70 & 50.72 \\
\hline \multirow[t]{2}{*}{ Diabetic status } & Diabetic & 109 & 49 & 44.95 & 43 & 39.45 \\
\hline & Nondiabetic & 444 & 143 & 32.21 & 84 & 18.92 \\
\hline
\end{tabular}

Note: ${ }^{a}$ The evaluation of treatment response was performed after $6-8$ cycles of chemotherapies. Patients who died during the therapies were excluded. $p$-values in bold $<0.05$. Abbreviations: PFS, progression-free survival; CSS, cancer-specific survival; IPI, international prognostic index; ECOG, Eastern Cooperative Oncology Group; PS, performance status; GCB, germinal center B-cell; LDH, lactate dehydrogenase; ULN, upper limit of normal; LLN, lower limit of normal; R-CHOP, rituximab, cyclophosphamide, doxorubicin, vincristine and prednisone; DA-EPOCH+R, dose-adjusted (etoposide, prednisone, vincristine, cyclophosphamide and doxorubicin) plus rituximab; Rmini CHOP, rituximab combined with low-dose CHOP; CR, complete remission; PR, partial remission. 


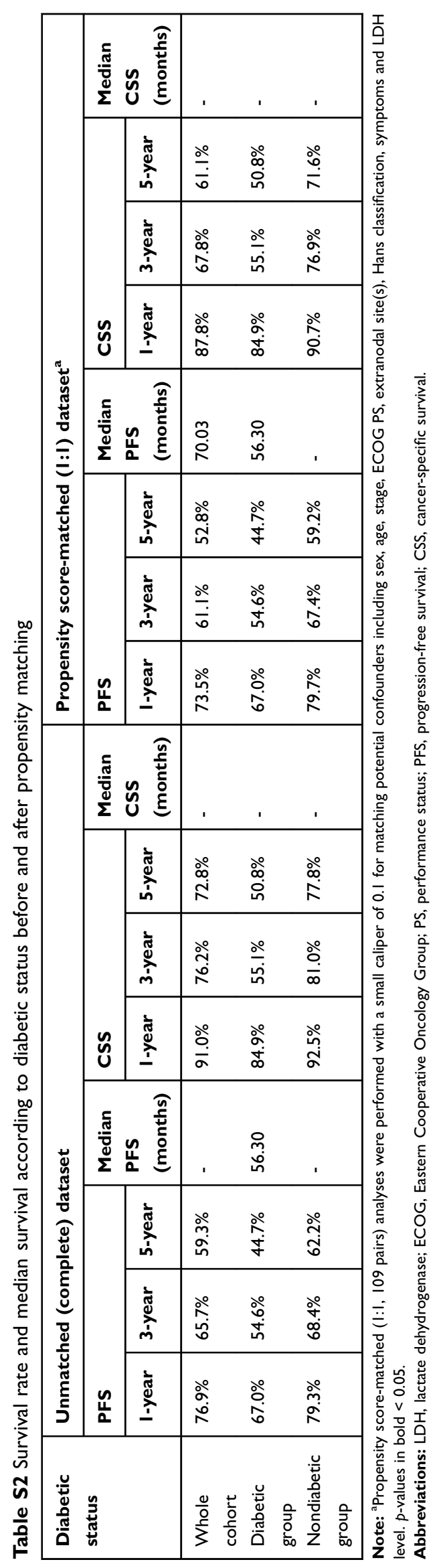




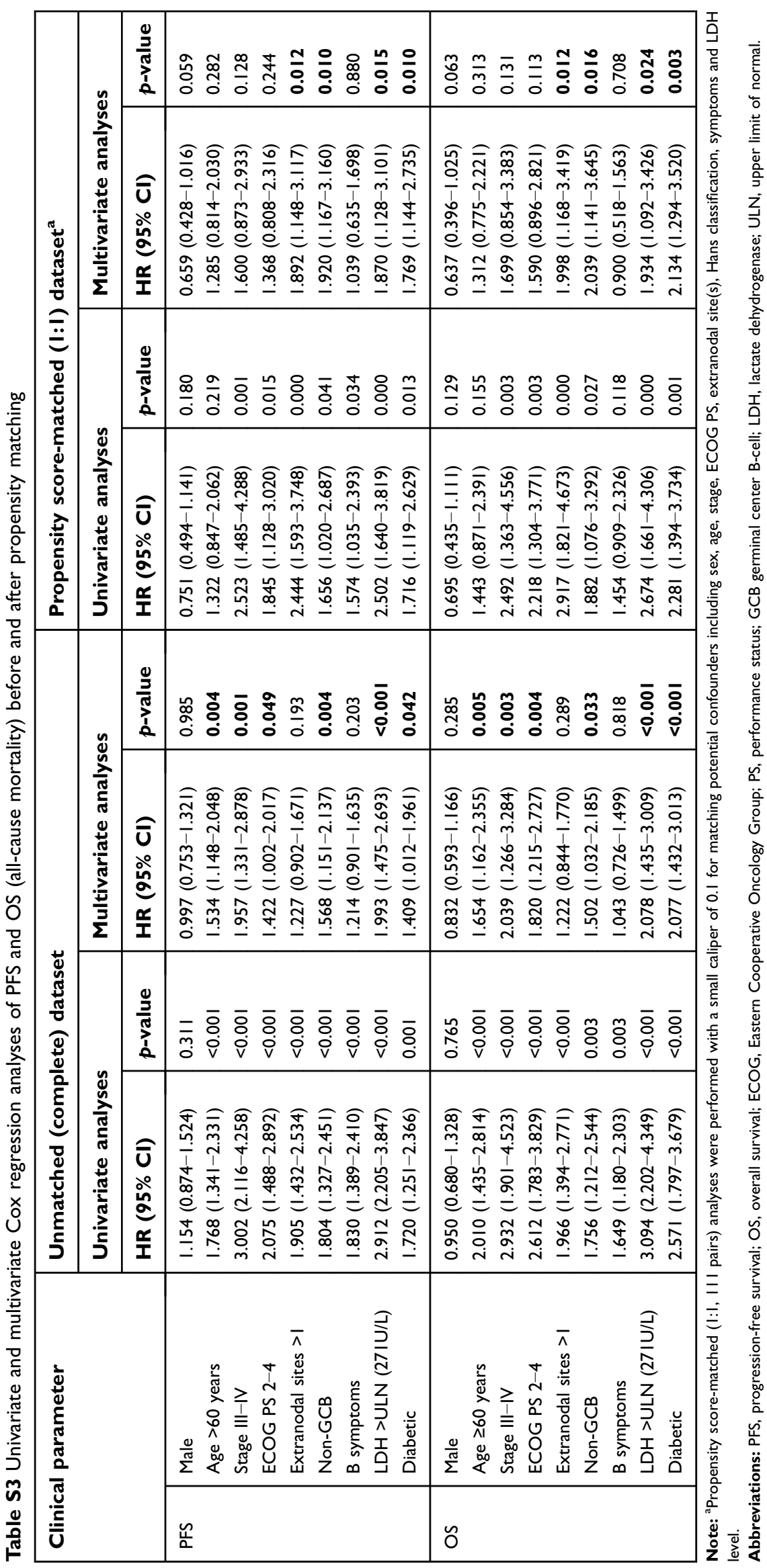




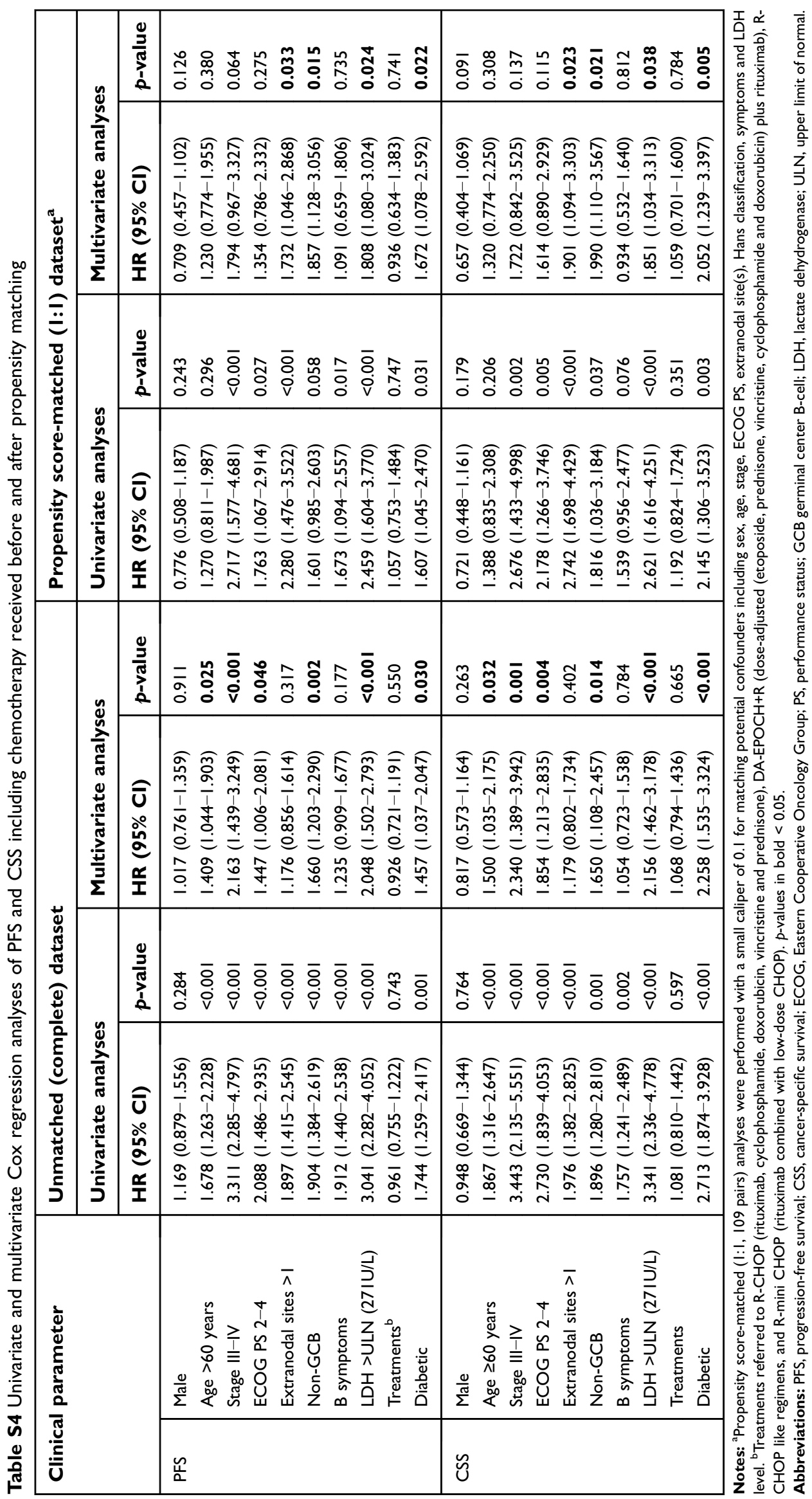



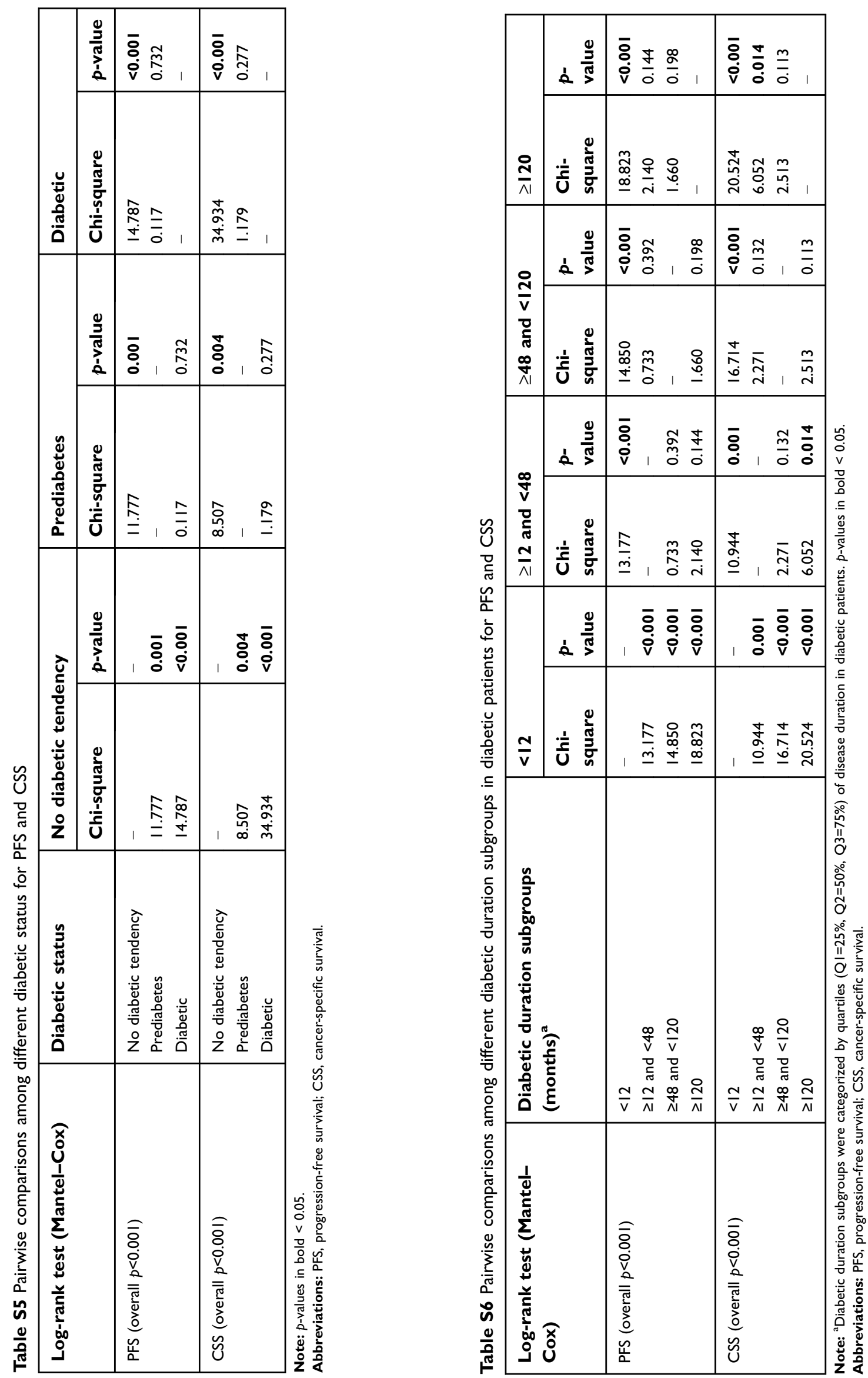

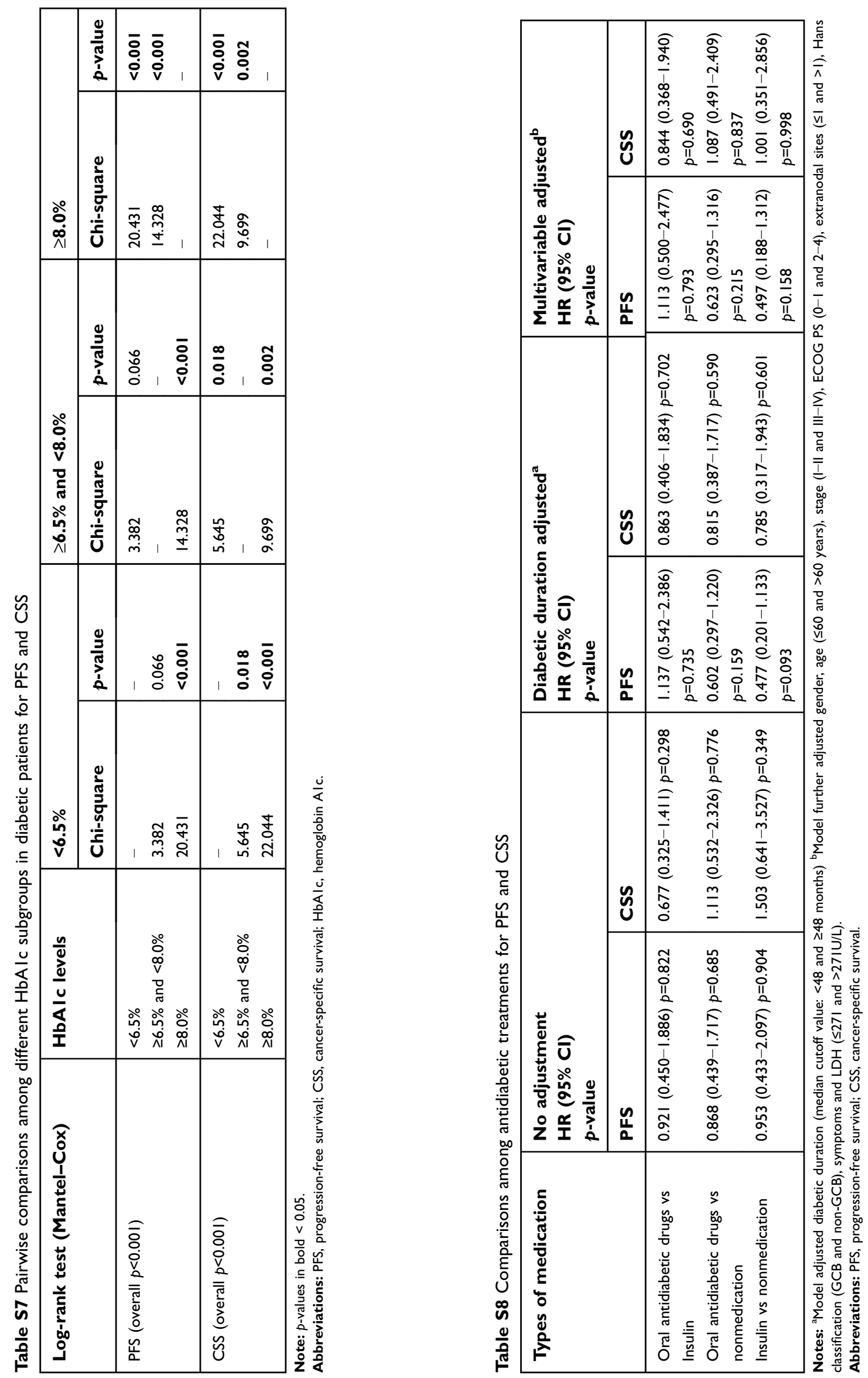
Table S9 Pairwise comparisons of DM-PI risk groups for PFS and CSS

\begin{tabular}{|c|c|c|c|c|c|c|c|}
\hline \multirow[t]{2}{*}{$\begin{array}{l}\text { Log-rank test } \\
\text { (Mantel-Cox) }\end{array}$} & \multirow[t]{2}{*}{ DM-PI risk groups } & \multicolumn{2}{|c|}{$\begin{array}{l}\text { Low risk } \\
\text { (DM-PI 0-I) }\end{array}$} & \multicolumn{2}{|c|}{$\begin{array}{l}\text { Intermediate risk } \\
\text { (DM-PI 2-3) }\end{array}$} & \multicolumn{2}{|l|}{$\begin{array}{l}\text { High risk } \\
\text { (DM-PI 4-6) }\end{array}$} \\
\hline & & Chi-square & $p$-value & Chi-square & $p$-value & Chi-square & $p$-value \\
\hline PFS (overall $p<0.001$ ) & $\begin{array}{l}\text { Low risk (DM-PI 0-I) } \\
\text { Intermediate risk } \\
\text { (DM-PI 2-3) } \\
\text { High risk (DM-PI 4-6) }\end{array}$ & $\begin{array}{l}- \\
51.951 \\
84.334\end{array}$ & $\begin{array}{l}- \\
<0.001 \\
<0.001\end{array}$ & $\begin{array}{l}51.951 \\
- \\
12.027\end{array}$ & $\begin{array}{l}<0.001 \\
- \\
0.001\end{array}$ & $\begin{array}{l}84.334 \\
12.027 \\
-\end{array}$ & $\begin{array}{l}<0.001 \\
0.001 \\
-\end{array}$ \\
\hline CSS (overall $p<0.001$ ) & $\begin{array}{l}\text { Low risk (DM-PI 0-I) } \\
\text { Intermediate risk } \\
\text { (DM-PI 2-3) } \\
\text { High risk (DM-PI 4-6) }\end{array}$ & $\begin{array}{l}- \\
39.720 \\
107.797\end{array}$ & $\begin{array}{l}- \\
<0.001 \\
<0.001\end{array}$ & $\begin{array}{l}39.720 \\
- \\
25.919\end{array}$ & $\begin{array}{l}<0.001 \\
- \\
<0.001\end{array}$ & $\begin{array}{l}107.797 \\
25.919 \\
-\end{array}$ & $\begin{array}{l}<0.001 \\
<0.001 \\
-\end{array}$ \\
\hline
\end{tabular}

Abbreviations: DM-PI, prognostic index including diabetes mellitus; PFS, progression-free survival; CSS, cancer-specific survival.

Note: $p$-values in bold $<0.05$.

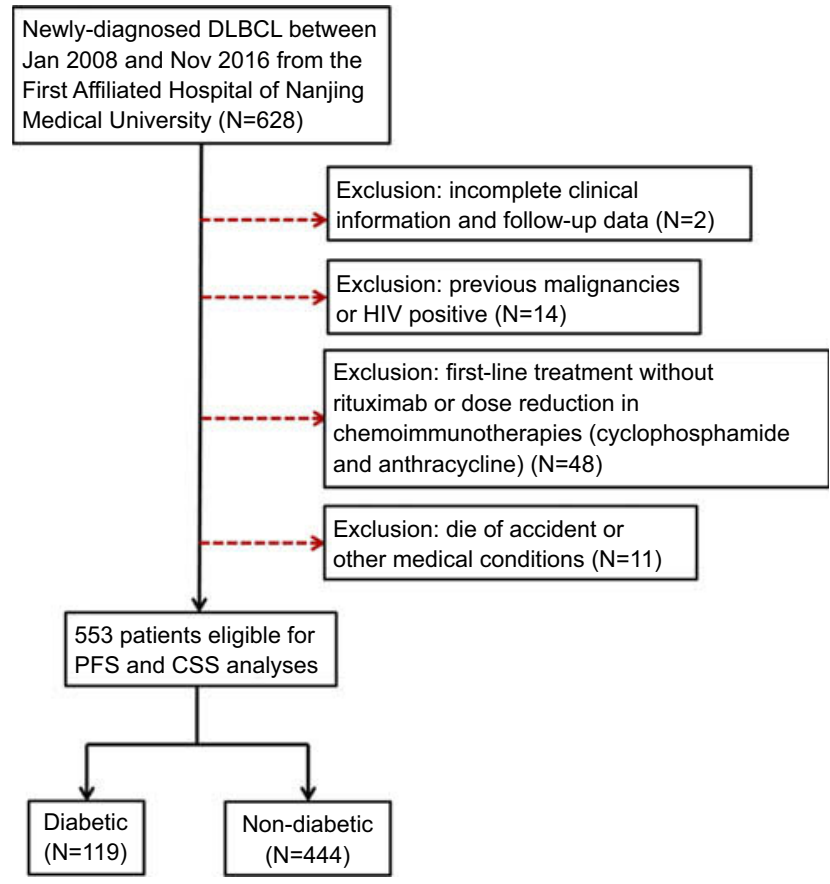

Figure SI Flowchart of the study population.

Abbreviations: DLBCL, diffuse large B-cell lymphoma; PFS, progression-free survival; CSS, cancer-specific survival. 
A Unmatched (complete) dataset

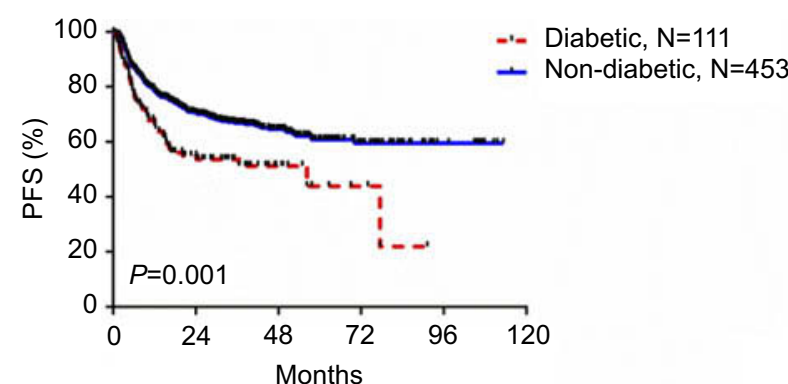

B Unmatched (complete) dataset

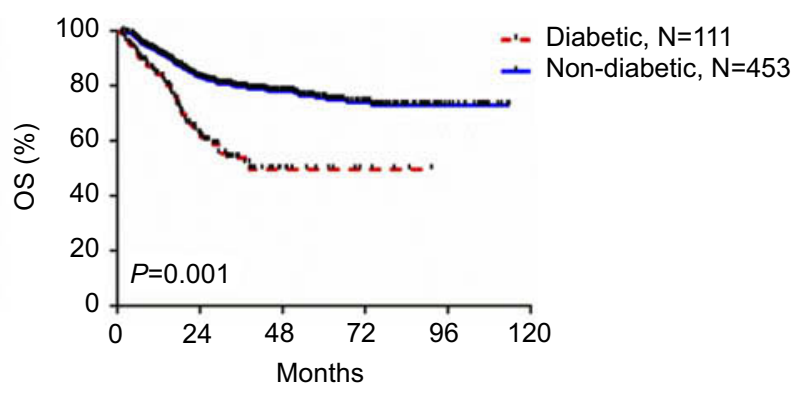

Number at risk

$\begin{array}{lllllll}\text { Diabetic } & 111 & 74 & 66 & 66 & 66 & 66\end{array}$

Non-diabetic $\begin{array}{llllll}453 & 382 & 367 & 361 & 360 & 360\end{array}$

\section{Propensity score-matched (1:1) dataset}

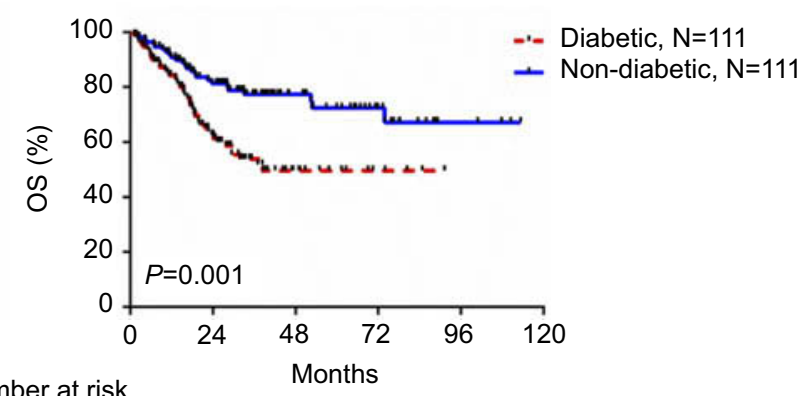

Number at risk

$\begin{array}{lllllll}\text { Diabetic } & 111 & 74 & 66 & 66 & 66 & 66\end{array}$

Non-diabetic $\begin{array}{llllll}111 & 92 & 89 & 87 & 86 & 86\end{array}$

$\begin{array}{lllllll}\text { Diabetic } & 111 & 64 & 62 & 61 & 60 & 60 \\ \text { Non-diabetic } & 111 & 79 & 77 & 74 & 74 & 74\end{array}$

Figure S2 Kaplan-Meier curves of PFS and OS (all-cause mortality) stratified by diabetic status before and after propensity matching. (A) PFS in unmatched (complete) dataset. (B) OS in unmatched (complete) dataset. (C) PFS in propensity score-matched (I:I) dataset. (D) OS in propensity score-matched (I:I) dataset.

Abbreviations: PFS, progression-free survival; OS, overall survival.

\section{Publish your work in this journal}

Cancer Management and Research is an international, peer-reviewed open access journal focusing on cancer research and the optimal use of preventative and integrated treatment interventions to achieve improved outcomes, enhanced survival and quality of life for the cancer patient.
The manuscript management system is completely online and includes a very quick and fair peer-review system, which is all easy to use. Visit http://www.dovepress.com/testimonials.php to read real quotes from published authors. 